\title{
Rapid Destruction of a Stratospheric Potential Vorticity Anomaly by Convectively Induced Inertial Instability during the Southern Wisconsin Extreme Flooding Event of 20 August 2018 $\mathcal{O}$
}

\author{
Shellie M. Rowe AND MatThew H. Hitchman \\ Department of Atmospheric and Oceanic Sciences, University of Wisconsin-Madison, Madison, Wisconsin
}

(Manuscript received 24 June 2019, in final form 7 August 2020)

\begin{abstract}
The stalling and rapid destruction of a potential vorticity (PV) anomaly in the upper troposphere-lower stratosphere (UTLS) by convectively detrained inertially unstable air is described. On 20 August 2018, 10-15 in. ( 0.3$0.4 \mathrm{~m}$ ) of rain fell on western Dane County, Wisconsin, primarily during 0100-0300 UTC 21 August (1900-2100 CDT 20 August), leading to extreme local flooding. Dynamical aspects are investigated using the University of Wisconsin Nonhydrostratic Modeling System (UWNMS). Results are compared with available radiosonde, radar, total rainfall estimates, satellite infrared, and high-resolution European Centre for Medium-Range Weather Forecasts (ECMWF) operational analyses. Using ECMWF analyses, the formation of the UTLS PV anomaly is traced to its origin a week earlier in a PV streamer over the west coast of North America. The rainfall maximum over southern Wisconsin was associated with this PV anomaly, whereby convection forming in the warm-upglide sector rotated cyclonically into the region. The quasistationarity of this rainfall feature was aided by a broad northeastward surge of inertially unstable convective outflow air into southeastern Wisconsin, which coincided with stalling of the eastward progression of the PV anomaly and its diversion into southern Wisconsin, extending heavy rainfall for several hours. Cessation of rainfall coincided with dilution of the PV maximum in less than an hour (2100-2200 CDT), associated with the arrival of negative PV in the upper troposphere. The region of negative PV was created when convection over Illinois transported air with low wind speed into northeastward shear. This feature is diagnosed using the convective momentum transport hypothesis.
\end{abstract}

KEYWORDS: Deep convection; Rainbands; Convective storms; Convective-scale processes; Potential vorticity; Mesoscale models

\section{Introduction}

a. Motivation and role of inertial instability in the UTLS

The occurrence of inertial instability in the upper tropospherelower stratosphere (UTLS) associated with midlatitude cyclones and how it relates to extreme precipitation events are not well understood. Numerous studies have investigated the role of positive potential vorticity (PV) anomalies in the UTLS associated with baroclinic systems, latent heat release, precipitation, and deep convection (e.g., Hoskins et al. 1985; Davis and Emanuel 1991; Craig and Cho 1992; Huo et al. 1999; Postel and Hitchman 1999; Ahmadi-Givi et al. 2004; Cavallo and Hakim 2009; Russell et al. 2012). The role of deep convection in developing regions of negative PV in the UTLS and their effect on stratosphere-troposphere exchange (STE) were studied by Rowe and Hitchman (2015). Rowe and Hitchman (2016) found that convectively produced negative PV leads to a poleward shift and intensification of the subpolar westerly jet.

The present work is motivated by witnessing damage to infrastructure, vegetation, and personal property associated with the 20 August 2018 Dane County, Wisconsin (WI), flooding event. On 21 August 2018, Dane County Emergency Management evacuated the villages of Black Earth, Cross

Supplemental information related to this paper is available at the Journals Online website: https://doi.org/10.1175/MWR-D-190213.s1.

Corresponding author: Shellie M. Rowe, rowe1@wisc.edu
Plains, and Mazomanie (Wisconsin Public Radio 2018), as a result of the $11-15$ in. $(0.3-0.4 \mathrm{~m} ; 1 \mathrm{in} . \approx 0.25 \mathrm{~m})$ of rain that fell, as shown in Fig. 1. The NWS estimated that 15.33 in. of rain fell in the town of Cross Plains (Fig. 1b). According to the National Weather Service (NWS) and the Wisconsin State Climatology Office, this was the largest 24-h rainfall in Wisconsin since 24 June 1946, when 11.72 in. fell on parts of Ashland County in northern Wisconsin. The rainfall amounts of 20 August 2018 exceeded all previous events in this region for the past 100 years, with the resulting floods earning the moniker "strange" in the statistical analysis of Smith et al. (2018). In this paper, we seek to understand the fundamental cause of the rapid dissolution of the stratospheric PV anomaly and why the cyclone stalled, creating a large rainfall accumulation. We also explore the role that inertial instability (air with negative PV) played in the poleward surge over eastern Illinois (IL), the effect on rainfall duration, and rapid dissolution of the stratospheric PV anomaly associated with this flooding event.

The role of inertial instability in the UTLS associated with extreme summertime rain events has been investigated in a few previous studies. Schultz and Knox (2007) investigated banded precipitation in the upper Midwest and concluded that inertial instability in the midtroposphere was perhaps the main factor in organizing these rainbands in a frontogenetic environment. Similarly, Knox (2003) and Knox and Hoggatt (1996) presented a case of banded clouds and precipitation over southern Wisconsin (WI) in which negative absolute vorticity was present where the bands formed. These cases however, were not associated with extreme precipitation events. Blanchard et al. (1998) presented a 

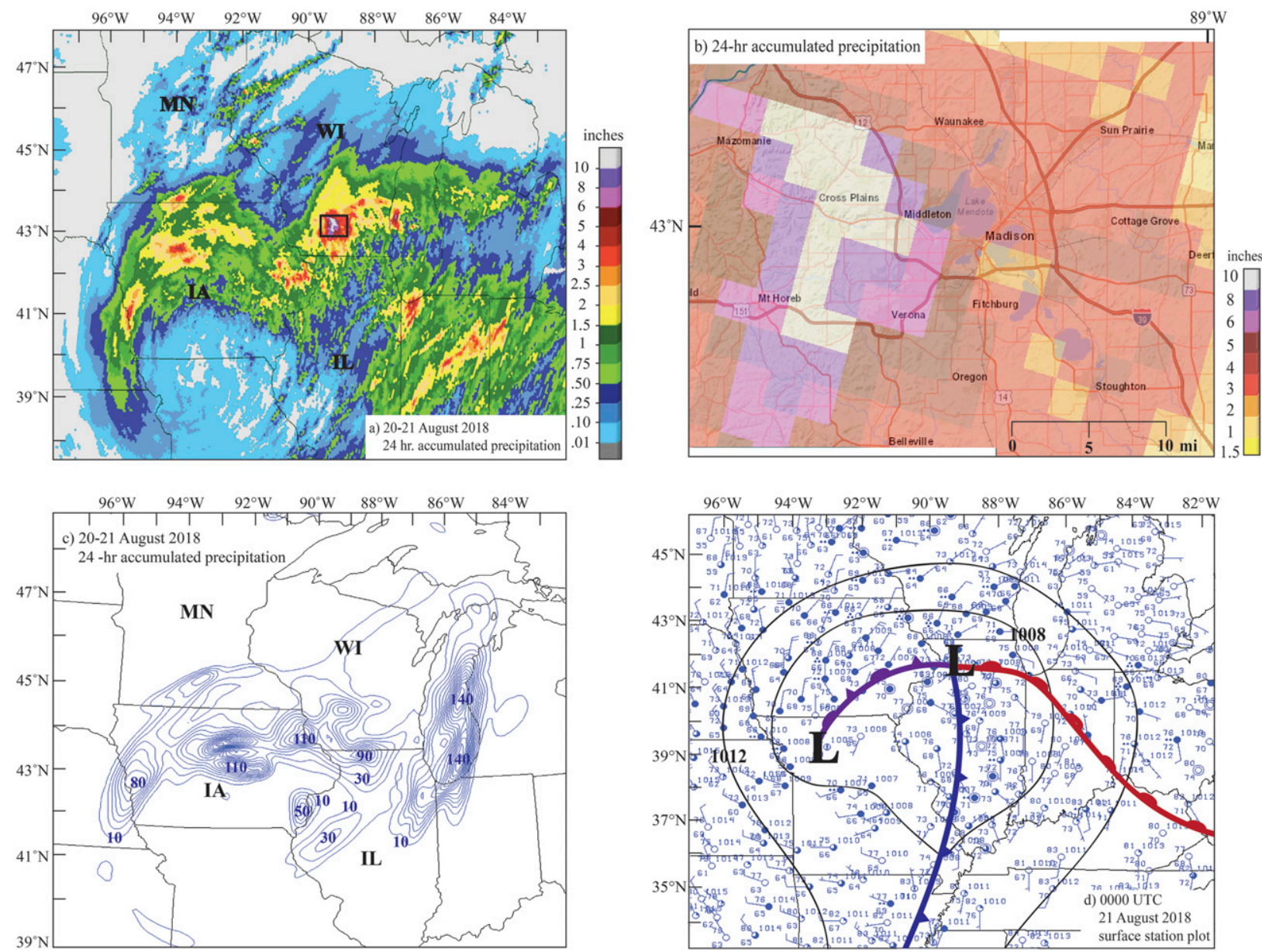

FIG. 1. (a) National Weather Service radar-derived estimate of 24-h accumulated precipitation over the region of study during 1200 UTC 20 Aug-1200 UTC 21 Aug 2018 (color bar, in.). (b) Zoom in [see black box in(a)], showing precipitation over Dane County, Wisconsin. (c) UWNMS model accumulated precipitation ( $\mathrm{mm}$, contours every $10 \mathrm{~mm}$ ) for the same 24-h period. (d) Surface station observations at 0000 UTC 21 Aug 2018, with overlays depicting frontal boundaries and isobars (black contours, interval: $4 \mathrm{hPa}$ ).

conceptual model showing how regions of upper-tropospheric inertial instability can contribute to the development of mesoscale convective complexes (MCCs). Seman (1994) concluded that inertial instability begins with momentum transport into deep convection creating negative absolute vorticity that extends into the upper troposphere. This idea constitutes a key ingredient in our dynamical interpretation of how this flooding event occurred.

Hitchman and Rowe (2017) showed that the orientation of UTLS PV dipoles in both midlatitude and tropical cyclones may be explained by updrafts bending midtropospheric horizontal vorticity into a horseshoe shape (Davies-Jones 1984; Chagnon and Gray 2009). Hitchman and Rowe (2019) extended this work, in application to convective asymmetries in tropical cyclones, and showed that the creation of UTLS PV dipoles may be understood in terms of the convective momentum transport hypothesis, where a mesoscale jet is produced near the top of the updraft due to the contrast in horizontal velocity in the updraft versus surrounding air. This general mechanism can be used to understand the creation of a jetlet, which opposes the ambient flow at a given level. The existence of a mesoscale jetlet implies the existence of an accompanying absolute vorticity dipole, with one member usually being inertially unstable. UTLS PV dipole structures are created by resolved advective flows in numerical simulations using the University of Wisconsin Nonhydrostatic Modeling System (UWNMS) at 10-km resolution. PV structures in European Centre for Medium-Range Weather Forecasts (ECMWF) operational analyses at $\sim 9-\mathrm{km}$ resolution are also shown.

When analyzing air in the UTLS, it is useful to consider the distribution of the vertical component of Ertel's PV: $P=(1 / \rho)(\partial \theta / \partial z)\left(f+\zeta_{3}\right)$, where $f=2 \Omega \sin \theta$ and $\zeta_{3}=\partial v / \partial x-$ $\partial u / \partial y$ is the vertical component of relative vorticity. In the midlatitudes, typical values of PV in the tropopause transition layer are 1-3 PVU, where $1 \mathrm{PVU}=1 \times 10^{-6} \mathrm{~K} \mathrm{~m}^{2} \mathrm{~kg}^{-1} \mathrm{~s}^{-1}$. During strong convection, UTLS PV dipole amplitudes can exceed \pm 50 PVU (Hitchman and Rowe 2017, 2019). This is to be expected for mesoscale vortices with horizontal shear magnitudes of $\sim \pm 20 \mathrm{~m} \mathrm{~s}^{-1}$ across $\sim 150 \mathrm{~km}$. In the present case, a deep 
PV dipole extends from the lower troposphere into the UTLS, peaking at $\sim-5$ and +3 PVU in the midtroposphere, is diagnosed in flows resolved in the UWNMS.

\section{b. Summertime flooding events and synoptic circumstances}

The role of midtropospheric vorticity maxima in extreme summertime precipitation events is well-documented. Schumacher and Johnson (2009) examined stationary precipitation for several Midwest flooding events and found that the relationship between the low-level jet and midlevel circulation is a factor in extremely heavy rainfall. Bosart and Sanders (1981) studied a midtropospheric PV maximum associated with a MCC that led to extensive flooding in parts of Pennsylvania. Stevenson and Schumacher (2014) studied extreme rainfall events in the Midwest over a period of 10 years and found that most 24-h extreme rainfall events were caused by MCCs that peak in frequency during June, July, and August. They found that only $\sim 30 \%$ were caused by synoptic-scale systems. The present case is a hybrid, common to the warm season, where convective complexes associated with a moderate midlatitude cyclone can become a dominant influence.

Zishka and Smith (1980) and Whittaker and Horn (1984) studied midlatitude cyclone tracks and found that, during northern summer, primary storm tracks typically originate in Alberta and Montana, and propagate toward Hudson Bay. The steady eastward track of the cyclone near $40^{\circ} \mathrm{N}$ in this study was perhaps slightly unusual for the month of August.

Many studies have linked extreme rainfall events with upper-level Rossby wave breaking and PV streamers (Romero et al. 1999; Martius et al. 2007; Sprenger et al. 2013). Harnik (2014) examined the spatial distribution of upper-level negative (cyclonic) vorticity events in the Southern Hemisphere and their seasonal evolution with respect to the jet stream. She concluded that, in both summer and winter, upper-level negative (cyclonic) vorticity events are associated with positive precipitation anomalies. Bithell et al. (1999) modeled the evolution of the 1 PVU isosurface and found that deformation and convergence can lead to the collapse of the high-PV features. Rowe and Hitchman (2016) studied negative PV anomalies and poleward momentum surges as they relate to jet intensification in the UTLS. The present work features the destruction of a stratospheric PV intrusion (a synoptic-scale positive PV anomaly) by the convective injection of negative PV air into the UTLS, and its influence on an extreme precipitation event over south-central WI.

\section{c. Modeling approach and structure of paper}

We first simulated this flooding event over western Dane County, WI with the UWNMS (Tripoli 1992) in order to diagnose local dynamical conditions involved in the flooding, and discovered that the UTLS PV anomaly was rapidly dissipated by convection in the model. We then acquired correlative observations, including radiosonde profiles, maps of radar reflectivity, satellite infrared, and total rainfall. For further comparison, we examined high-resolution ECMWF analyses, which proved to be useful in determining the upstream evolution of the PV anomaly. A key benefit of using the UWNMS to diagnose this rapidly evolving convective event is the 20 -min temporal resolution of output archival, compared to the 6-h resolution of the ECMWF data.

The flooding event was found to be associated with a compact UTLS PV anomaly propagating from the west. In the UWNMS simulation, the outbreak of deep convection over IL was associated with a poleward surge of inertially unstable air, which at first diverted the stratospheric PV anomaly into southern WI, and then led to a strikingly rapid destruction of the PV anomaly. The evolution of the distribution of PV in the UTLS was similar in the UWNMS simulation and ECMWF analyses. This paper describes the spatial and temporal relationship among the poleward surge, convective outbreak of inertially unstable air, duration and location of intense precipitation over southern WI, and its cessation, which coincided with the breakdown of the stratospheric PV intrusion.

This paper is organized as follows. Section 2 describes the UWNMS simulations, ECMWF analyses, and auxiliary datasets used in this study. The local synoptic situation is described in section 3, together with a comparison of UWNMS and correlative data. The origin, upstream evolution, and rapid destruction of the UTLS PV anomaly as seen in ECMWF data are described in section 4 , which emphasizes synoptic-scale features. The role of convection over IL in deflecting the PV maximum northward into WI and its subsequent rapid erosion is discussed in section 5, which emphasizes mesoscale features. In section 6 , creation of inertially unstable air by convective transport of low-speed air into proximity with fast-moving air is described using the convective momentum transport hypothesis. Conclusions are given in section 7 .

\section{Data and analysis}

This event was simulated with the UWNMS (Tripoli 1992), and initialized with National Centers for Environmental Prediction (NCEP) Global Forecast System (GFS) data. The UWNMS has been used to investigate STE (Hitchman et al. 1999, 2004), midlatitude severe weather events (Rowe and Hitchman 2015, 2016), and tropical cyclones (Hitchman and Rowe 2017, 2019). Primary results are shown using a resolution of $10 \mathrm{~km} \times 10 \mathrm{~km} \times 300 \mathrm{~m}$, for a domain $\sim 1500 \mathrm{~km}$ on a side covering the upper Midwest. Results from a 20-km-resolution run were very similar to results from the $10-\mathrm{km}$-resolution run to be shown, for the primary features of the resolved flow that are discussed in this paper. The top of the model was set to $25 \mathrm{~km}$. This is suitable for the present application, which is focused on the UTLS centered near $10 \mathrm{~km}$ altitude. The model was initialized at 1200 UTC 20 August 2018 by interpolating GFS $0.5^{\circ}$-resolution data throughout the volume, and run for $36 \mathrm{~h}$ until 0000 UTC 22 August 2018, updating the side boundaries with GFS data every $3 \mathrm{~h}$. In this simulation, the turbulent kinetic energy prediction scheme was turned on, the surface layer parameterization with a two-layer soil model was turned off, and the convective parameterization was turned off. The radiative transfer code was called every $15 \mathrm{~min}$ and the standard microphysics package included rain, pristine crystals, and snow (Tripoli 1992). The visualization software Vis5d was used to view the structure and dynamical features associated with this event in UWNMS output fields.

This study makes use of high-resolution ECMWF operational analyses, available beginning in January 2016, with a grid 
spacing of $9 \mathrm{~km}\left(0.08^{\circ}\right)$ (ECMWF 2016; rda.ucar.edu). ECMWF operational analyses were used to illustrate the upstream development of the PV maximum and for comparison with UWNMS features. Within this dataset, we used the ECMWF Operational 6-hourly isobaric analysis. The $\sim 9-\mathrm{km}$ resolution of this ECMWF dataset is comparable to the $10-\mathrm{km}$ resolution chosen for the UWNMS simulation. Since the temporal resolution of these ECMWF isobaric analyses is $6 \mathrm{~h}$, the 15-min temporal resolution of the UWNMS simulation is essential for describing the complex evolution of the PV anomaly over WI in just a few hours.

A map of estimated 24-h precipitation was obtained from the Advanced Hydrological Prediction Center (Advanced Hydrological Prediction Center 2020). Radar reflectivity maps and satellite radiance maps were made from NEXRAD Level II and GOES-16 datasets, using the NOAA Weather and Climate Toolkit, which is distributed by the National Centers for Environmental Information. Radiosonde soundings, available at 0000 and 1200 UTC, for Davenport, Iowa (IA) (DVN), and Lincoln, IL (ILX), were obtained as auxiliary data associated with the GFS data package. This package also included a surface station map, to which isobars and frontal features were added using analysis from the Weather Prediction Center. The small size and rapid dissolution of the cyclone was such that it fit in between the locations and times of radiosonde launches. However, the northward flow at ILX confirms the poleward surge in the UTLS seen over eastern IL in the UWNMS.

\section{Precipitation distribution, synoptic setting, and model validation}

Figure 1a shows a view of the 24-h accumulated precipitation in the upper Midwest during 20-21 August 2018. The region of greatest rainfall (box in Fig. 1a) is highlighted in Fig. 1b. In the town of Cross Plains, more than $10 \mathrm{in}$. of rain fell in only a few hours. Figure 1d shows surface station data and the locations of fronts, isobars, and low pressure centers from the Weather Prediction Center, at 0000 UTC 21 August ( 1900 CDT), near the beginning of the period of most intense precipitation over southern WI. A region of weak low pressure is seen extending from northern Missouri to northern IL, with rain and overcast conditions near the cold front in central IL and in a commashaped arc extending from eastern WI into western IA. This cyclonic low pressure center was vertically continuous with the stratospheric PV anomaly, the evolution of which is the focus of this study.

The distribution of 24-h accumulated rainfall for the period 1200 UTC 20 August to 1200 UTC 21 August 2018 in the UWNMS is shown in Fig. 1c. Similar features in the radar observations and numerical model estimates of the rainfall distribution include the arc of heavy precipitation extending from eastern Nebraska into southern Minnesota and northeastern IA, the maximum over southwest WI, and the northeastward streaks across Indiana and Lake Michigan. Rainfall amounts in the UWNMS are generally less than the amounts estimated from radar (Figs. 1a,c). Although the detailed locations of precipitation maxima in the UWNMS sometimes departed somewhat from observed rainfall maxima, the synoptic-scale and large mesoscale features of the storm are essentially correct.

Chen and Dai (2019) showed significant differences between zonal mean rainfall estimates obtained from satellites and those calculated with global climate models (their Fig. 4). Rodrigo et al. (2018), in a study of the distribution of rainfall over Sri Lanka, tuned the Weather Research and Forecasting Model (WRF) to achieve fair agreement for average rainfall rates, but significant mesoscale differences in the locations of rainfall maxima were a characteristic of each simulation (e.g., their Fig. 5). Recent studies have explored the resolution dependence of accuracy in quantitative precipitation forecasting in complex convective systems down to subkilometer scale (e.g., Nielsen and Schumacher 2020). Here a 10-km-resolution UWNMS simulation is used to diagnose the synoptic and resolved mesoscale dynamics underlying the stalling and rapid dissolution of the PV maximum associated with convection over eastern IL.

The evolution of clouds and precipitation from $\sim 1800$ to 2030 CDT 20 August 2018 over the model domain is shown in Fig. 2, including satellite infrared and Milwaukee radar reflectivity images. At 2300 UTC 20 August, the infrared pattern (Fig. 2a) shows a meridionally oriented band of clouds associated with the cold front over central IL (Fig. 1d), and a classic "comma head" of rainfall to the north of the surface low. Particularly cold cloud tops may be seen over northeastern IA and southwestern WI (cf. with Figs. 1a,c). The Milwaukee radar at this time (Fig. 2c) showed an area of reflectivity in central IL, which is nearly collocated with the convective event in the UWNMS to be discussed below. It also shows arcs of precipitation maxima from Iowa into southern WI and over central WI.

By 0130 UTC (2030 CDT) 21 August (Figs. 2b,d,e), the cold front had moved eastward to the Indiana border, with the highest, coldest clouds seen over southern WI. Figure $2 \mathrm{e}$ focuses on southern WI, showing a region of heavy rainfall in western Dane County, with radar reflectivity exceeding $50 \mathrm{~dB} Z$. Locations exceeding $50 \mathrm{~dB} Z$ correspond to radiances less than $\sim 20 \mathrm{~mW} \mathrm{~m}^{-2} \mathrm{sr}^{-1}\left(\mathrm{~cm}^{-1}\right)^{-1}$, with cloud tops reaching $\sim 12 \mathrm{~km}$.

Movies of radar reflectivity and GOES-16 radiance during 1400-2300 CDT over the upper Midwest are shown in Figs. S1 and $\mathrm{S} 2$ in the online supplemental material. By watching their evolution, one can see the hourly contribution to the total rainfall patterns shown in Figs. 1a and 1c. The time of coldest cloud tops over western Dane County occurred during 00000200 UTC 21 August (1900-2200 CDT 20 August), in agreement with the duration of heaviest precipitation over the region. The convective cell over central IL in Figs. 2c and 2d is seen in Fig. S1 to propagate northeastward toward Lake Michigan, yielding the precipitation streak evident in Figs. 1a and 1c. This feature corresponds with the locations of stations showing rain in the surface map (Fig. 1c), and supports the existence of the convective feature in the UWNMS in this region.

Maps of reflectivity in the La Crosse radar during 1300-2400 CDT (Fig. S1) were used to estimate hourly rainfall rates. The period of heaviest precipitation occurred over western Dane County during 1600-2300 CDT 20 August 2018, with most 


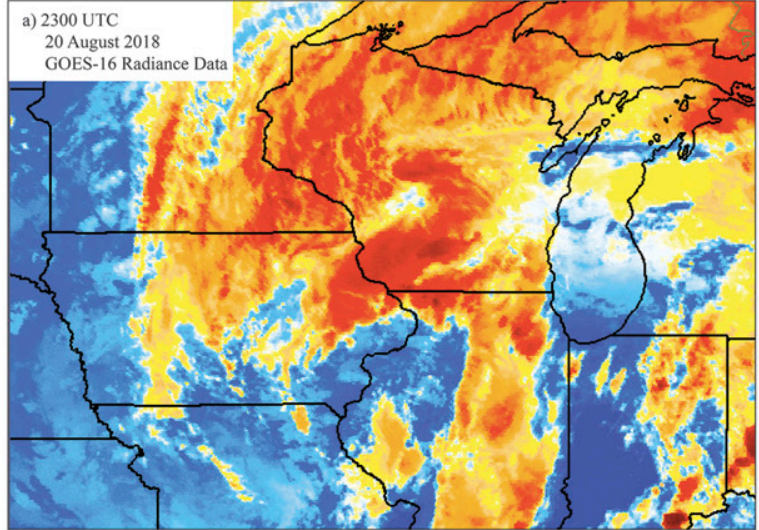

$\operatorname{Rad}\left(\mathrm{mW} \mathrm{m}^{-2} \mathrm{sr}^{-1}\left(\mathrm{~cm}^{-1}\right)^{-1}\right)$

$\begin{array}{cccccc}18.29 & 32.69 & 47.08 & 61.48 & 75.88 & 90.27\end{array}$

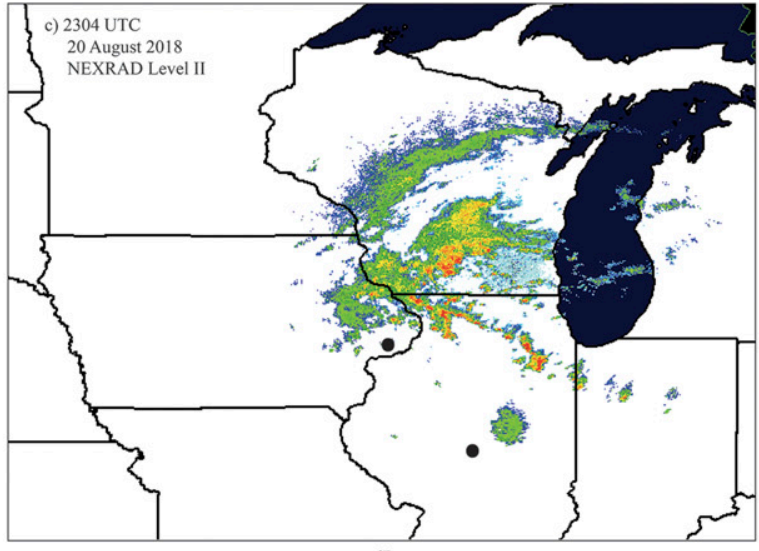

$\|_{756555453525155}$

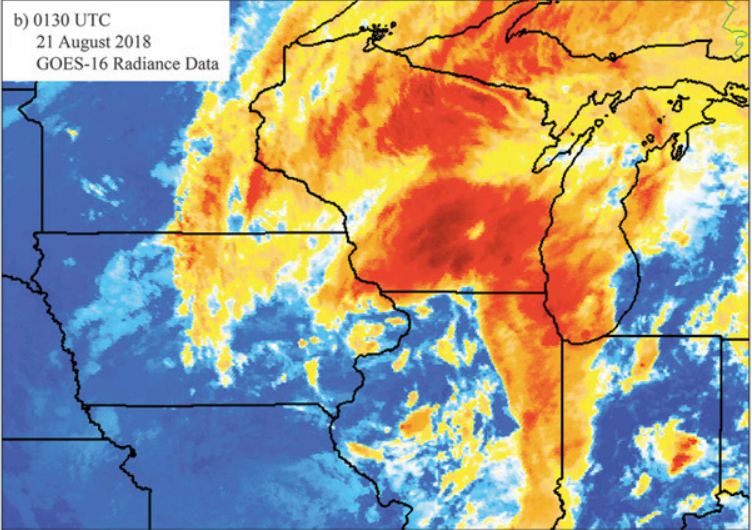

$\operatorname{Rad}\left(\mathrm{mW} \mathrm{m}^{-2} \mathrm{sr}^{-1}\left(\mathrm{~cm}^{-1}\right)^{-1}\right)$

\begin{tabular}{cccccc}
\hline & 1 & 1 & 1 & 1 & \\
18.29 & 32.69 & 47.08 & 61.48 & 75.88 & 90.27
\end{tabular}
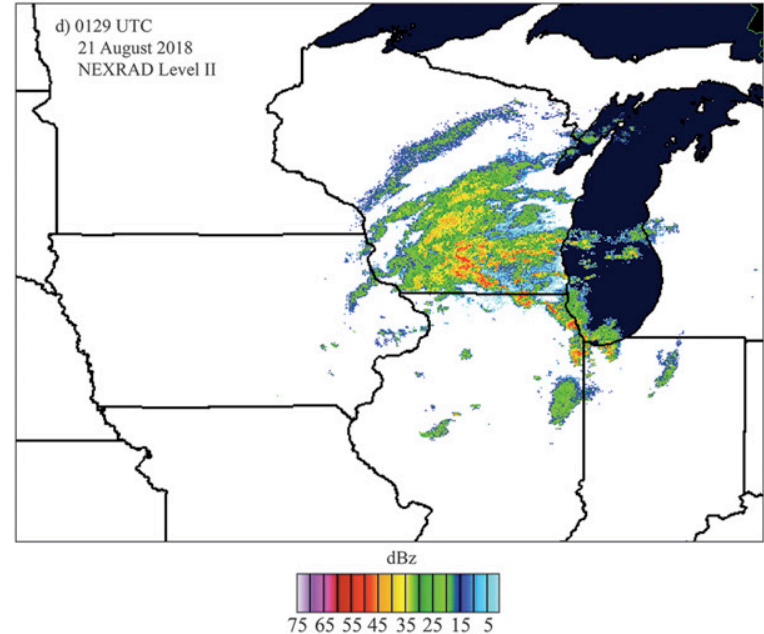

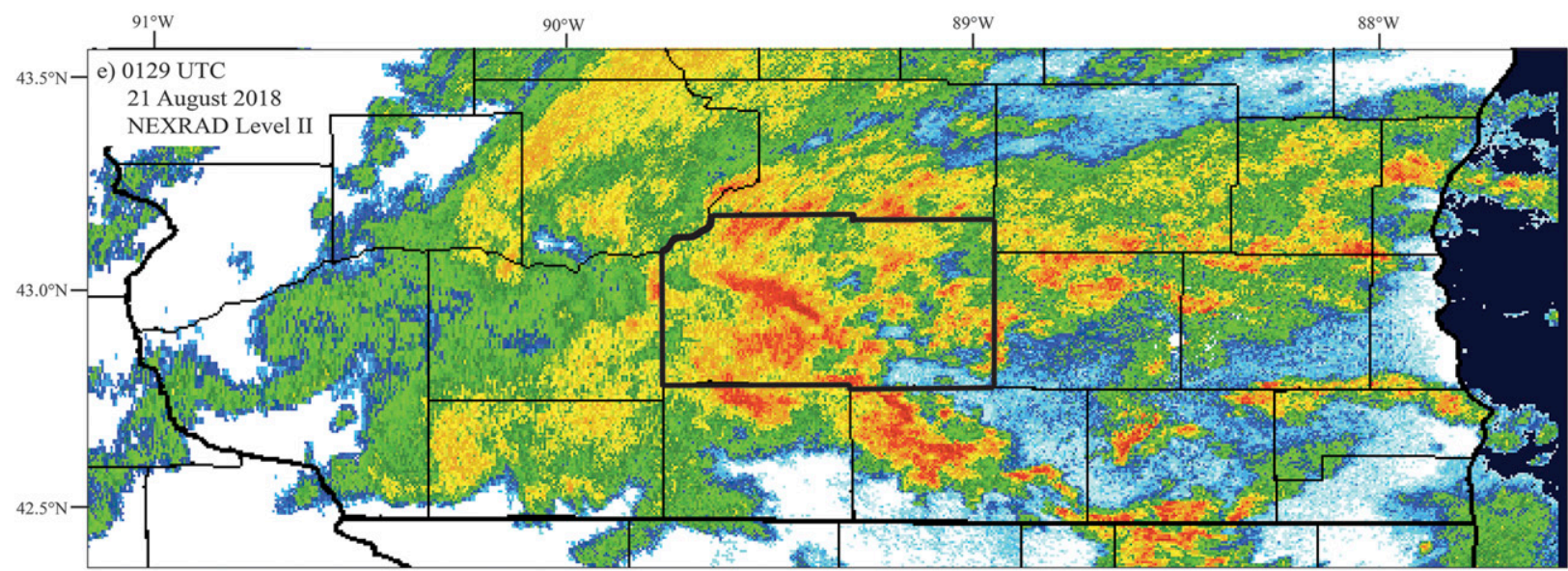

$\mathrm{dBz}$

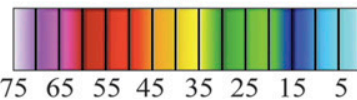

FIG. 2. Evolution from (left) $\sim 1800$ to (right) $\sim 2030$ CDT over the region of study of the distribution of (top) GOES-16 radiance data [color bar, $\mathrm{mW} \mathrm{m}^{-2} \mathrm{sr}^{-1}\left(\mathrm{~cm}^{-1}\right)^{-1}$ ] and (middle) NEXRAD Level II radar reflectivity at station KMKX (Milwaukee, WI; color bar, interval: $10 \mathrm{dBz}$ ) with specific times: (a) 2300 UTC 20 Aug, (b) 2304 UTC 20 Aug, (c) 0130 UTC 21 Aug, and (d) 0129 UTC 21 Aug 2018. (e) As in (d), but focused on southern WI. The black dots show the locations of the radiosonde stations at Davenport, IA, and Lincoln, IL (Fig. 3). The border of Dane County is highlighted in (e). 

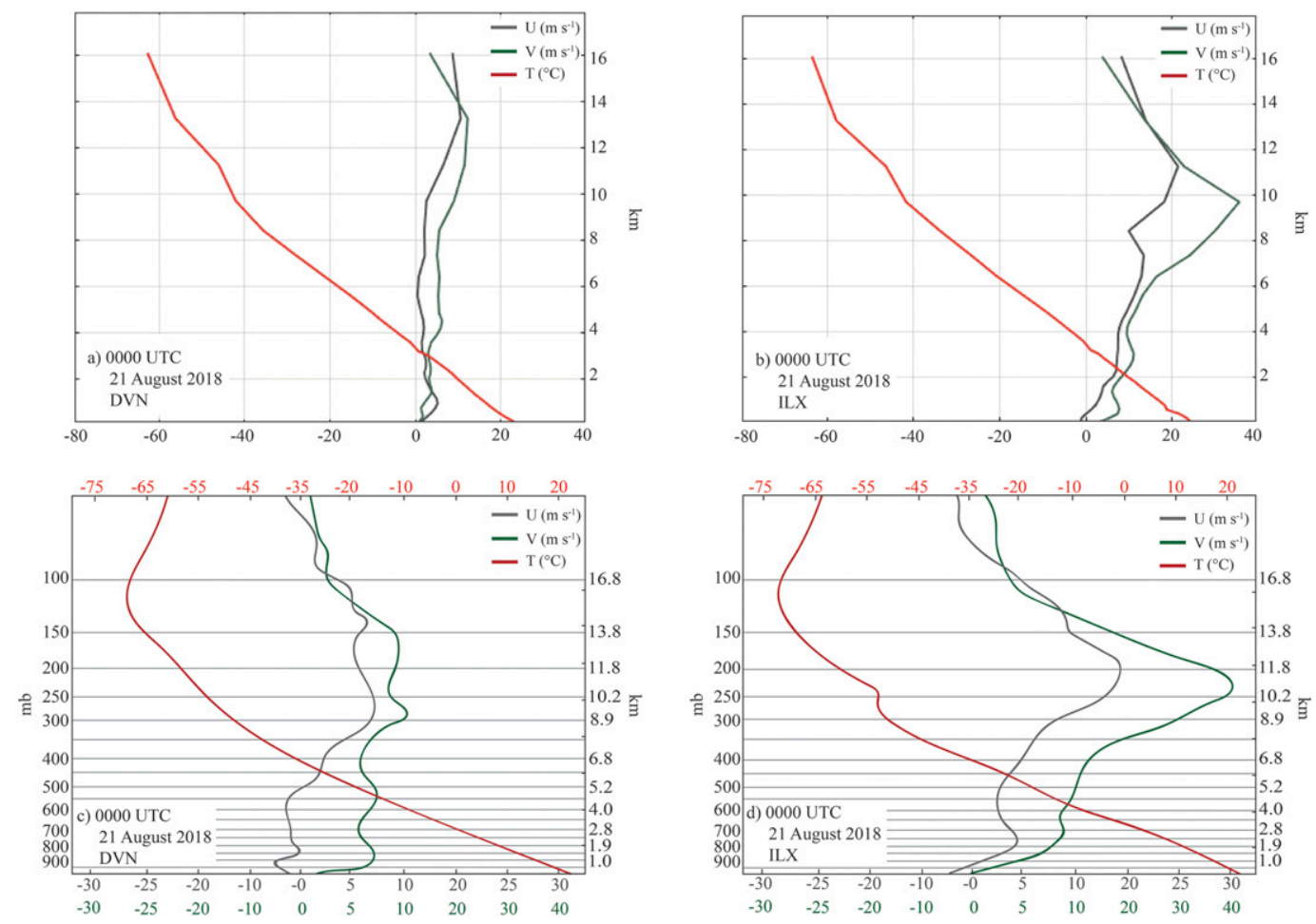

FIG. 3. Comparison of (a),(b) radiosonde and (c),(d) UWNMS profiles of temperature $\left({ }^{\circ} \mathrm{C}\right)$, zonal wind $\left(\mathrm{m} \mathrm{s}^{-1}\right)$, and meridional wind $\left(\mathrm{m} \mathrm{s}^{-1}\right)$ for 0000 UTC (1900 CDT) 21 Aug 2018 at (left) Davenport, IA (DVN; $41.61^{\circ} \mathrm{N}, 90.57^{\circ} \mathrm{W}$ ) and (right) Lincoln, IL (ILX; $40.15^{\circ} \mathrm{N}, 89.33^{\circ} \mathrm{W}$ ). The radiosonde plots were made by obtaining pressure-level data in GEMPAK and mapping them onto log-pressure coordinates in MATLAB for comparison with the UWNMS altitudecoordinate profiles made with Vis5d. In the UWNMS profiles, the temperature coordinate is at the top.

of it falling during 1800-2100 CDT (2300 UTC 20 August0200 UTC 21 August). Following Young et al. (1999) and Orellana-Alvear et al. (2017), the relationship between $R$ and radar reflectivity parameter $Z$ is taken to be $Z=300 R^{1.4}$, or $R=0.017 Z^{0.714}$. Since $\mathrm{dB} z=10 \log _{10} Z, Z=10^{0.1 \mathrm{~dB} z}$, so that $R=0.01710^{0.0714 \mathrm{~dB} z}$. Using this method, $\mathrm{dB} z=40$ corresponds to $0.5^{\prime \prime} \mathrm{h}^{-1}, 45 \mathrm{dBZ}$ to $1.5^{\prime \prime} \mathrm{h}^{-1}$, and $50 \mathrm{dBZ}$ corresponds to $2.5^{\prime \prime} \mathrm{h}^{-1}$. The resulting estimates of rainfall, based on visual judgment of the $\mathrm{dBZ}$ color bar during each of the $10 \mathrm{~h}$ of 1300 2300 CDT are the following: $0.5,0.5,0.8,1.0,1.5,2.0,2.0,2.5$, 1.5 , and $0.5 \mathrm{in}$., which sum to $12.8 \mathrm{in} .(\sim 0.3 \mathrm{~m})$. This is in agreement with the 24-h total shown in Fig. 1a. Of the 12.8 in. total, $\sim 10.5 \mathrm{in}$. fell during the $6 \mathrm{~h}$ of $1600-2000 \mathrm{CDT}$, with $\sim 6.5 \mathrm{in}$. falling during the $3 \mathrm{~h}$ of $1800-2100 \mathrm{CDT}$. For comparison with maps of the evolution of PV in the UWNMS, precipitation exceeding $1.0 \mathrm{in}$. $(25 \mathrm{~mm}) \mathrm{h}^{-1}$ fell during 1600 2000 CDT (2100 UTC 20 August-0300 UTC 21 August).

The locations of the radiosonde stations at Davenport, IA, near the low pressure center (Fig. 1d) and Lincoln, IL, just to the east of the cold front, are shown in Fig. 2c. A comparison with UWNMS temperature, zonal wind, and meridional wind profiles is shown in Fig. 3 for 0000 UTC (1900 CDT) 21 August 2018. The surface temperature at DVN (Fig. 3a), was $\sim 22^{\circ} \mathrm{C}$, with temperatures of $\sim-62^{\circ} \mathrm{C}$ near $16-\mathrm{km}$ altitude, in both the radiosonde and UWNMS (Fig. 3c). Weak zonal winds $\left(<5 \mathrm{~m} \mathrm{~s}^{-1}\right)$ are found below $\sim 8 \mathrm{~km}$, with westerlies of $\sim 5-10 \mathrm{~m} \mathrm{~s}^{-1}$ in the 9-14-km layer. Moderate southerly winds of $\sim 5 \mathrm{~m} \mathrm{~s}^{-1}$ in the lower troposphere reach $\sim 10 \mathrm{~m} \mathrm{~s}^{-1}$ in the UTLS (Figs. 3a,c).

At the location of ILX (Figs. 3b,d), the radiosonde and UWNMS temperature profiles were similar to each other and similar to those at DVN (Figs. 3a,c). The wind profiles were markedly different at ILX, compared to at DVN, consistent with its location to the east of the stratospheric PV anomaly. At ILX, wind speeds increase from $\sim 5 \mathrm{~m} \mathrm{~s}^{-1}$ in the lower troposphere to $\sim 40 \mathrm{~m} \mathrm{~s}^{-1}$ in the UTLS, with direction toward the north-northeast, as might be expected for its location in the warm upglide sector with an imminent cold-frontal passage.

This agreement between radiosonde and UWNMS wind profiles at ILX supports a primary feature in the UWNMS, the poleward surge of air from the convective element over central IL into southeastern WI.

\section{Upstream evolution and rapid destruction of the UTLS PV anomaly}

\section{a. Upstream evolution}

The origins of the rolled-up stratospheric PV streamer associated with this flooding event can be traced to its formation over the U.S. West Coast one week earlier. Figure 4 shows the evolution of $200 \mathrm{hPa}$ PV over the 8-day period of $0000 \mathrm{UTC} 13$ August-0000 UTC 21 August 2018, with a time interval of $48 \mathrm{~h}$. An elongated PV streamer is evident at 0000 UTC 13 August 

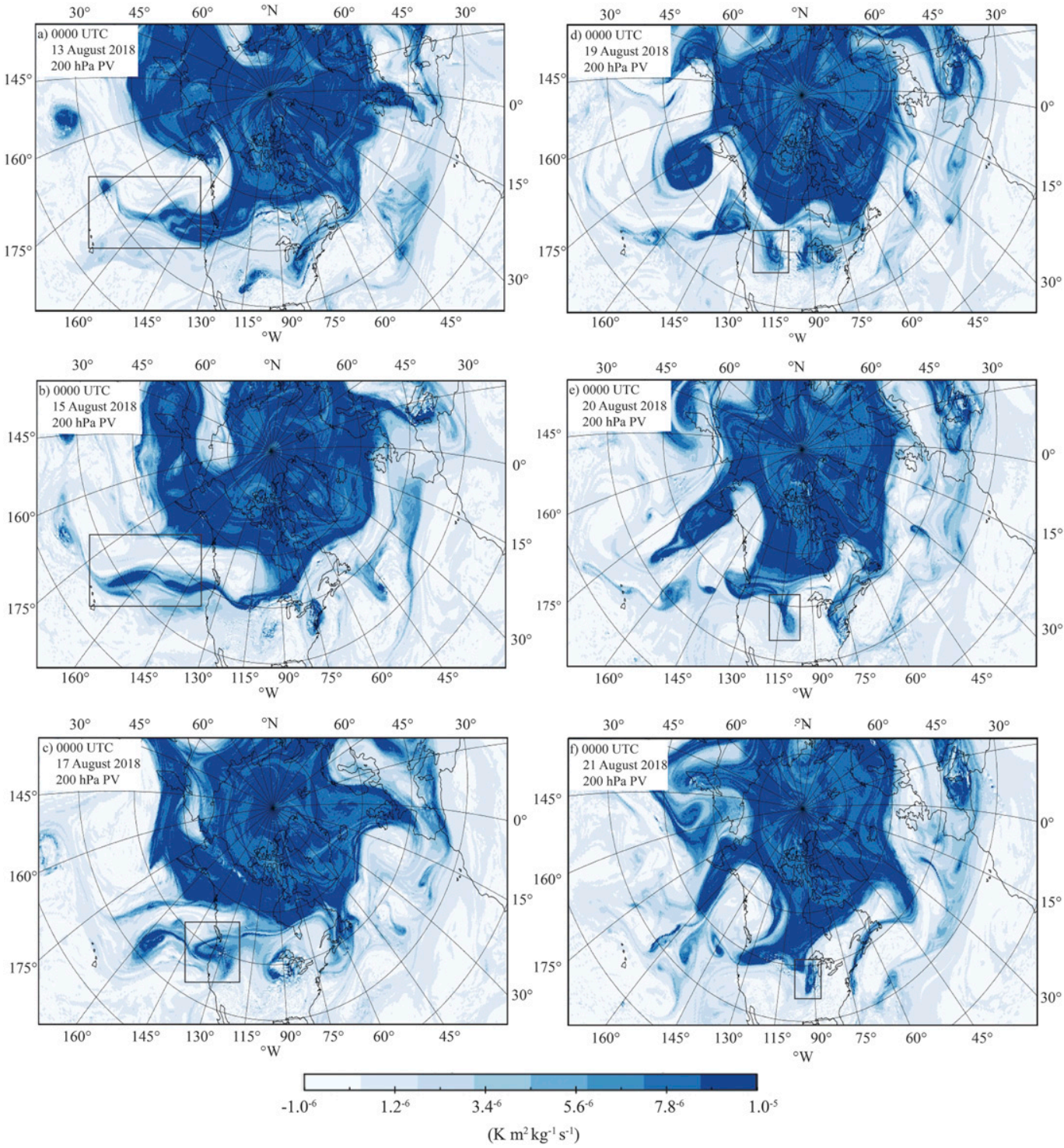

$\left(\mathrm{K} \mathrm{m}^{2} \mathrm{~kg}^{-1} \mathrm{~s}^{-1}\right)$

FIG. 4. Evolution of UTLS PV anomaly at $200 \mathrm{hPa}$, as seen in $0.08^{\circ}$-resolution ECMWF data: (a) 0000 UTC 13 Aug, (b) 0000 UTC 15 Aug, (c) 0000 UTC 17 Aug, (d) 0000 UTC 19 Aug, (e) 0000 UTC 20 Aug, and (f) 0000 UTC 21 Aug 2018 (color bar, $\mathrm{K} \mathrm{m}^{2} \mathrm{~kg}^{-1} \mathrm{~s}^{-1}$ ).

(Fig. 4a), arcing anticyclonically from the Yukon over the Pacific Northwest, and westward to $\sim 30^{\circ} \mathrm{N}, 175^{\circ} \mathrm{W}$. The overall morphology is a signature of anticyclonic Rossby wave breaking (McIntyre and Palmer 1983; Hitchman and Huesmann 2007), with the PV streamer breaking up into a series of rolled-up vortices. This may be consistent with barotropic instability theory, whereby, if the meridional gradient of PV switches sign across a zonally oriented PV filament or streamer, a wavy perturbation can grow by accessing kinetic energy associated with speed differences in the mean flow.

The evolution of this PV streamer over the Pacific is highlighted with an identically positioned rectangle for 13 and 15 August (Figs. 4a,b). The PV streamer in the eastern part of this rectangle rolled up cyclonically into a triangular shape over the
Pacific Northwest on 17 August (Fig. 4c), with a strand still connected to the polar vortex over Hudson Bay at this level. Then weak westerly flow began to advect this PV anomaly slowly eastward, where it rolled up and tightened over Wyoming (Fig. 4d). This feature then tracked eastward over the central Great Plains, where it developed a classic "fiddlehead" shape over Iowa by 0000 UTC 20 August (Fig. 4e). By 0000 UTC 21 August the PV anomaly was losing its rolled-up shape, extending diffusely toward Lake Superior (Fig. 4f).

The progression of the $\mathrm{PV}$ anomaly from $\sim 135^{\circ}$ to $\sim 95^{\circ} \mathrm{W}$ in 4 days corresponds to a zonal trace speed $c_{x} \sim 10^{\circ}$ day $^{-1}$ $\sim 7 \mathrm{~m} \mathrm{~s}^{-1}$, due to the mild eastward ambient flow of order $1 \mathrm{~m} \mathrm{~s}^{-1}$ and small Rossby propagation term (of order $0.1 \mathrm{~m} \mathrm{~s}^{-1}$ for $\left.L_{x} \sim 1000 \mathrm{~km}\right)$. It will be shown in section $5 \mathrm{~b}$ that, by the 

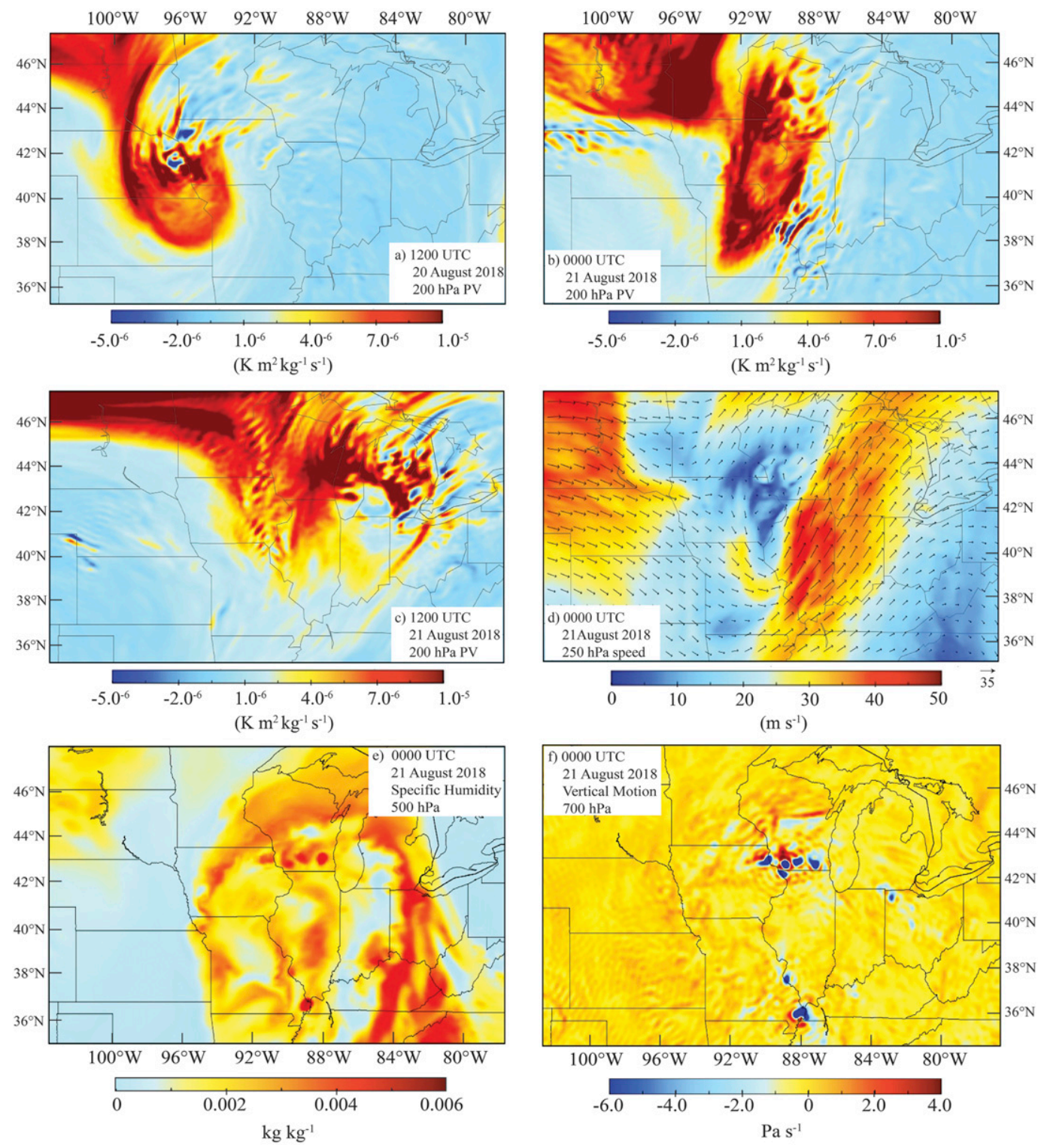

FIG. 5. ECMWF $0.08^{\circ} \times 0.08^{\circ}$ operational forecasts of $200 \mathrm{hPa} \mathrm{PV}$ at (a) $1200 \mathrm{UTC} 20 \mathrm{Aug}$, (b) $0000 \mathrm{UTC} 21 \mathrm{Aug}$, and (c) 1200 UTC 21 Aug 2018 (color bar, $\mathrm{K} \mathrm{m}^{2} \mathrm{~kg}^{-1} \mathrm{~s}^{-1}$ ). ECMWF operational analyses at $0000 \mathrm{UTC} 21$ Aug of (d) 250-hPa wind speed (color bar, $\mathrm{m} \mathrm{s}^{-1}$ ) and wind vectors ( $m a x$ vector: $35 \mathrm{~m} \mathrm{~s}^{-1}$ ), (e) 500-hPa specific humidity (color bar, $0.1 \mathrm{~kg} \mathrm{~kg}^{-1}$ ), and (f) vertical motion at $700 \mathrm{hPa}\left(\right.$ color bar, $\mathrm{Pa} \mathrm{s}^{-1}$ ).

time this high-PV lens reached the upper Midwest, it was separated vertically by several kilometers from air in the stratosphere with similar PV values. The diameter of this PV lens is $\sim 600 \mathrm{~km}$, suggesting a Rossby radius of deformation (Holton 2006) of $L_{R} \sim 300 \mathrm{~km}$. Since $L_{R}=c / f \sim\left(L_{z} N\right) /(2 \pi f)$ and $N / f \sim 200$, this is compatible with a characteristic inertiagravity wave vertical wavelength of $L_{z} \sim 10 \mathrm{~km}$ and horizontal phase speed $c \sim 30 \mathrm{~m} \mathrm{~s}^{-1}$.

\section{b. Evolution of PV anomaly over the upper Midwest}

The northward diversion and destruction of the UTLS PV anomaly by a convective momentum surge featuring inertially unstable air is shown Figs. 5-7. Figures 5a-c show the evolution of ECMWF 200-hPa PV in the upper Midwest during the 24-h period 1200 UTC 20 August-1200 UTC 21 August. Also shown are ECMWF 250-hPa wind speed and vectors (Fig. 5d), along with 500-hPa specific humidity (Fig. 5e) and 700-hPa vertical motion (Fig. 5f) for 0000 UTC 21 August. In Figs. 5a-c the blue-yellow transition occurs at $\sim 2$ PVU, with values in the PV "fiddlehead," or rolled-up filament, reaching $\sim 10$ PVU. At 1200 UTC 20 August (Fig. 5a), the PV anomaly was centered over eastern Nebraska, with a distinct connection to the "parent" stratospheric high-PV region over Canada. 

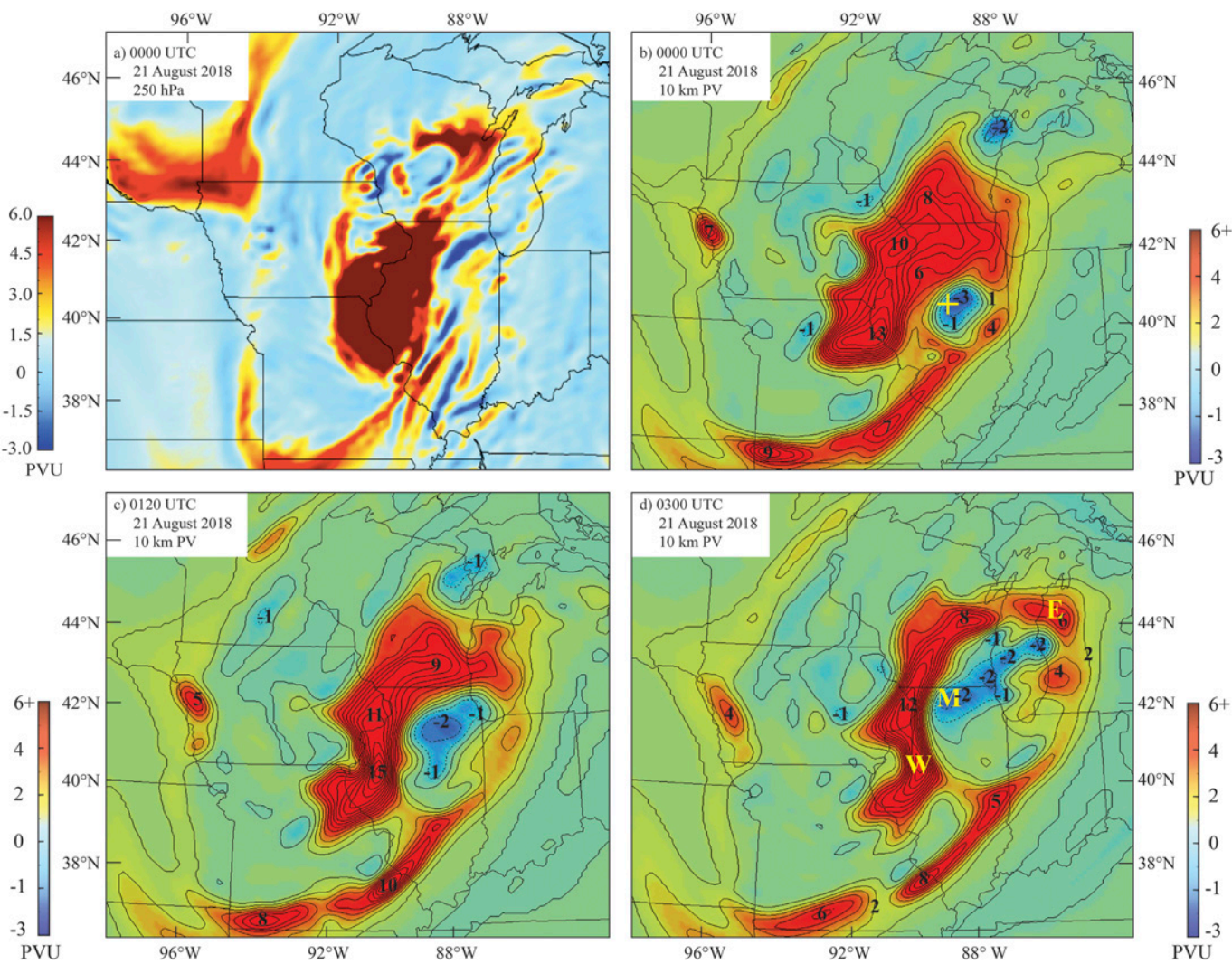

FIG. 6. Comparison of (a) ECMWF 250-hPa PV (color bar, $\mathrm{K} \mathrm{m}^{2} \mathrm{~kg}^{-1} \mathrm{~s}^{-1}$ ) and (b) UWNMS 10-km PV (color bar, PVU) at 0000 UTC 21 Aug 2018. The rapid destruction of the 10-km PV anomaly in the UWNMS is seen in (c) 0120 and (d) 0300 UTC 21 Aug 2018. The location of NWS radiosonde station ILX shown in Fig. 9 is indicated with a yellow plus sign in (b). The locations of the UWNMS profiles shown in Fig. 11 are indicated in (d).

By 0000 UTC 21 August in the ECMWF depiction (Fig. 5b), the positive PV anomaly had lost its fiddlehead shape and had spread out toward the north, extending from Southern Missouri to Lake Superior. Note the occurrence of patches of negative PV and elongated, gravity wave-like features over IL. A broad region of strong winds can be seen at $250 \mathrm{hPa}$, extending from southern IL northeastward over Michigan and Lake Huron (Fig. 5d). The northward diversion of high-PV air into WI from Fig. 5a to Fig. 5b is contemporaneous with the onset of intense rainfall. This meridional elongation also coincided with a slowing of eastward progression of the PV anomaly, with the center at $42^{\circ} \mathrm{N}$ moving eastward $\sim 500 \mathrm{~km}$ during the 12-h period (between Figs. 5a and 5b), but with little eastward progression during the next $12 \mathrm{~h}$ (between Figs. $5 \mathrm{~b}$ and $5 \mathrm{c}$ ). This broad poleward surge penetrated the PV maximum, creating a significant region of low PV centered over southern Lake Michigan (Fig. 5c).

By 1200 UTC 21 August (Fig. 5c), the once well-organized PV anomaly had weakened and spread horizontally (cf. Figs. 5a,c), with gravity wave-like features throughout the region, as generated in the ECMWF analyses. The circular area of low PV over the southern tip of Lake Michigan in Fig. 5 c coincides with the maximum poleward surge in Fig. $5 d$. Thus, during the period of maximum rainfall, the eastward progression of the UTLS PV maximum was effectively diverted into southern WI by this convectively accelerated northward surge. This process likely contributed to the quasistationarity of the location of maximum rainfall over western Dane County.

Figure 5e shows the distribution of ECMWF 500-hPa specific humidity, with concentrated maxima over southern WI and central IL, and a ring of moist air around the periphery of the storm. The ECWMF 700-hPa vertical motion field shows evidence of convective elements over southern WI and over the southern tip of IL (Fig. 5f). This latter feature, and lack of convection over central IL in the ECMWF depiction, disagree with observations and the UWNMS (Figs. 1a,c,d and 2).

A comparison between 200-hPa ECMWF PV and 10-km UWNMS PV at 0000 UTC 21 August is shown in Figs. 6a and $6 \mathrm{~b}$. The location of the PV maximum, its shape, and extent are similar in the two depictions. Note the collocation of the spiralshaped trailing PV streamer through southern Missouri and into Minnesota. However, the negative PV region near the convection over central IL (Fig. 6b) is not diagnosed by ECMWF (Fig. 6a).

Figures $6 \mathrm{~b}-\mathrm{d}$ follows the destruction of the UTLS PV anomaly during the 3 -h period 0000-0300 UTC 21 August in the UWNMS simulation. Figure S3 shows a movie of the 


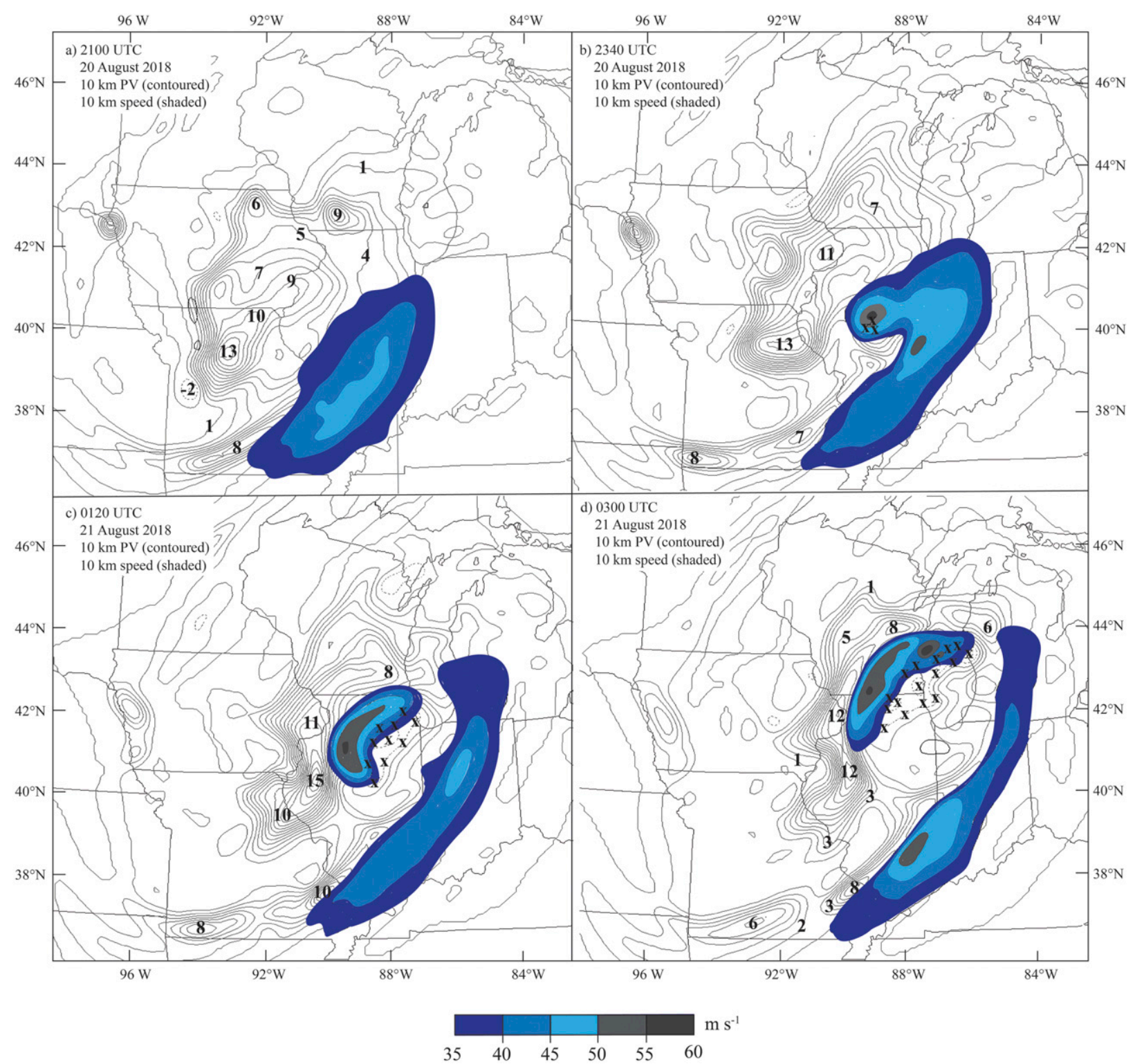

FIG. 7. Sequence of $10-\mathrm{km}$ PV (contour interval: 1 PVU) and wind speed (color bar, range $35-60 \mathrm{~m} \mathrm{~s}^{-1}$ ) in the UWNMS simulation at (a) 2100 UTC 20 Aug, (b) 2340 UTC 20 Aug, (c) 0120 UTC 21 Aug, and (d) 0300 UTC 21 Aug 2018. The X marks indicate regions where $\mathrm{PV}$ is less than 0.

detailed temporal evolution and rapid destruction of the stratospheric PV anomaly. At 0000 UTC (Fig. 6b), about an hour after the rainfall rate began to exceed $1.0 \mathrm{in}^{.} \mathrm{h}^{-1}$, the PV maximum can be seen extending into southern WI. A negative PV anomaly is seen over central IL, with a diameter of $\sim 200 \mathrm{~km}$, surrounded by a ring of positive PV. By 0120 UTC (Fig. 6c), the time of the maximum rainfall rate of $2.5 \mathrm{in.} \mathrm{h}^{-1}$, the negative PV region has spread and moved northward, but the PV maximum over southwestern WI remains strong. By 0300 UTC, the circular negative PV anomaly extended from northwestern IL to southwestern Michigan and well into southeast WI (Fig. 6d). The injection of negative PV air into the eastern part of the UTLS cyclonic PV maximum has turned the original lens of PV into a toroidal-shaped PV maximum in the UTLS. Its vertically limited extent will be shown in the next section. The northern half of the high-PV lens was diverted from its eastward path, with high-PV air being displaced northward into WI by the poleward surge. This process will be further illustrated with trajectories in the next section.

\section{c. Inertial instability and flow structure}

The coevolution of $10-\mathrm{km}$ wind speed, PV, and regions of inertial instability during 1600-2000 CDT (2100 UTC 20 August-0300 UTC 21 August) is shown in a time sequence in Fig. 7. At 1600 CDT (2100 UTC, Fig. 7a), a northeastward wind speed maximum in excess of $40 \mathrm{~m} \mathrm{~s}^{-1}$ is seen along the 
southeast side of the PV anomaly, extending from southern Missouri to Lake Michigan. High-PV air (contours) has entered southern WI, coinciding with an increase in precipitation rate. At 1740 CDT (2340 UTC, Fig. 7b), a notch of low wind speed has been introduced over central IL, with $\mathrm{X}$ marks indicating a region of inertial instability on its poleward, leading edge. The northeastward wind speed anomaly is starting to split into two maxima, one on either side of the low-wind speed notch (Fig. 7b).

Over the next $1 \mathrm{~h} 40 \mathrm{~min}$, this region of high-wind speed air spread into southeastern WI, at the head of a growing mass of inertially unstable air on its equatorward flank (Fig. 7c). This relationship between a poleward surge of inertially unstable air and a head of high-wind speed air is very similar to that shown for the Super Tuesday midlatitude cyclone (Rowe and Hitchman 2016). In both cases, inertially unstable air accelerated poleward and then eastward, effectively displacing the westerly jet poleward. The time of 2020 CDT (0120 UTC 21 August) was chosen to correspond with the time of maximum rainfall in radar images (Fig. 7c, Fig. S1). This poleward surge of low-PV air coincided with the period of intense rainfall in southern WI, eroding the eastern side of the stratospheric PV anomaly, while diverting the remaining part northward.

By 2200 CDT (0300 UTC 21 August), the region of anomalously high wind speed at the leading edge of the region of negative PV had overspread southeastern WI, and the region of high PV was displaced to the west of Dane County (Fig. 7d). The region of low PV has spread into a bubble shape, creating a ring of high PV around it, with northeastward jets on both sides of the low-PV anomaly. The arrival of the surge of low-PV air over south-central WI, displacing the high-PV air, coincided with the rapid decrease of precipitation over the next hour.

The flow structure in the UWNMS near the time of maximum rainfall (0120 UTC 21 August or 2030 CDT 20 August) is shown at altitudes of 4, 6, 8, 10,11, and $12 \mathrm{~km}$ in Fig. 8. Cyclonic circulation is seen in the midtroposphere (Figs. 8a,b), centered near southeastern Iowa. A broad poleward surge is seen to the east of the cyclone center, over IL and into southeastern WI, with northnortheastward flow increasing with height. A region of weak flow is seen over central IL, collocated with a convective updraft (cf. next section), reaching to $\sim 12 \mathrm{~km}$ (Fig. 8f). This region corresponds to the minimum in speed between the two maxima in Fig. 7c. Poleward of the updraft, the upper-tropospheric flow accelerates northward toward southeastern WI (Fig. 8).

\section{Structure of poleward surge}

a. Creation of UTLS negative PV anomaly in the UWNMS

A quasi-meridional section through the primary updraft in the UWNMS at 0120 UTC 21 August 2018 was chosen to depict the relationship among PV, vertical motion, wind speed, and meridional streamlines associated with the convective event over central IL, with the orientation of the section shown in Fig. $8 \mathrm{~d}$. The updraft is located near $40^{\circ} \mathrm{N}, 88.7^{\circ} \mathrm{W}$, reaching a maximum of $5 \mathrm{~m} \mathrm{~s}^{-1}$ near $5.5 \mathrm{~km}$, and penetrating to $\sim 12-\mathrm{km}$ altitude (Figs. 9b,d). The updraft is embedded in northeastward flow, with a field of gravity waves evident in the $10-15-\mathrm{km}$ layer above the updraft, extending in a pattern upward and poleward (Fig. 9d).
A deep PV dipole is seen extending from $\sim 3 \mathrm{~km}$ to the tropopause near $11 \mathrm{~km}$, centered near the updraft at $40^{\circ} \mathrm{N}$, with values reaching -5 and +3 PVU near 7-km altitude (Fig. 9a). The level of maximum anomaly strength occurs near the level of maximum updraft. There is a notable poleward tilt with altitude and areal expansion of the negative PV anomaly (Fig. 9a), coinciding with an axis of weak wind speed (Fig. 9c), and consistent with the pattern of streamlines in the meridional plane (Fig. 9d). The areal expansion with time of the negative PV anomaly near $10 \mathrm{~km}$ is depicted in Fig. 6.

The tropopause ( $~ 2-P V U$ contour) in Fig. 9a is rather complex, due to the presence of the UTLS cyclonic PV lens and the effects of convective detrainment events. This meridional section intersects the positive $\mathrm{PV}$ toroid, highlighted by the 5-PVU isertel, in the $8-12-\mathrm{km}$ layer near $42^{\circ}-44^{\circ} \mathrm{N}$ and near $39^{\circ} \mathrm{N}$ (Fig. 9a). Note how the PV maxima associated with the toroid near $10-\mathrm{km}$ altitude are separated vertically from similar "background" levels of PV in the stratosphere by several kilometers (Fig. 9a).

A striking signature of the updraft is that it contains air with horizontal speeds of less than $15 \mathrm{~m} \mathrm{~s}^{-1}$, leading to a vaulted structure of low-wind speed air in the upper troposphere (Figs. 9b,c). A region of weaker wind speed (relative to surroundings) coincides with the poleward-tilted region of inertially unstable air, at the head of which lies a region of poleward motion exceeding $45 \mathrm{~m} \mathrm{~s}^{-1}$ (Figs. 9a,c). The axis of largest negative PV (Fig. 9a) lies exactly where the poleward increase in speed maximizes (solid curved line in Fig. 9c). From $40^{\circ}$ to $42^{\circ} \mathrm{N}$, the air accelerates from 15 to $45 \mathrm{~m} \mathrm{~s}^{-1}$ in the uppermost troposphere. Spatially varying acceleration due to inertial instability is expected to be associated with enhanced divergence/convergence and increased generation of gravity waves.

Profiles of $u, v$, and $w$ in the updraft (location " $U$ " in Fig. 8d) and $100 \mathrm{~km}$ to the north (location "N" in Fig. 8d) are shown in Figs. 10a and 10b. The updraft in the UWNMS peaks at $5 \mathrm{~m} \mathrm{~s}^{-1}$ near 6-km altitude (Fig. 10a). Both horizontal wind components increase with altitude throughout the troposphere, consistent with the northeastward surge that is occurring over eastern IL (Figs. 7c and 8a,b). At location "N" $100 \mathrm{~km}$ to the north (Fig. 10b), there is no convective updraft and southwesterly flow was observed to increase upward throughout the layer, with a diminution of zonal flow (more southerly flow) in the layer 7-12 km ( 400-250 hPa).

In the mid- to upper troposphere, both horizontal wind components are less than $15 \mathrm{~m} \mathrm{~s}^{-1}$ in the updraft (Fig. 10a) but exceed $20 \mathrm{~m} \mathrm{~s}^{-1} 100 \mathrm{~km}$ to the north (Fig. 10b), and downstream $200 \mathrm{~km}$ to the northeast (Fig. 10c; location "D" on Fig. 8d). This reflects the vaulted structure of low-wind speed air in the updraft seen in Fig. 9c. A strong outflow jet in the 1214-km layer is seen at the location of the updraft (Fig. 10a). The outflow jet in Fig. 10a subsides $\sim 2 \mathrm{~km}$ as it flows toward the northeast, being centered near $11 \mathrm{~km}$ over the southern tip of Lake Michigan (Fig. 10c). This behavior is similar to outflow from convective complexes in tropical cyclones discussed in Hitchman and Rowe (2019).

b. Structure of PV maximum at 0300 UTC 21 August 2019

By 0300 UTC 21 August 2019, the initial PV maximum anomaly in the UTLS was converted from a lens shape to a ring 


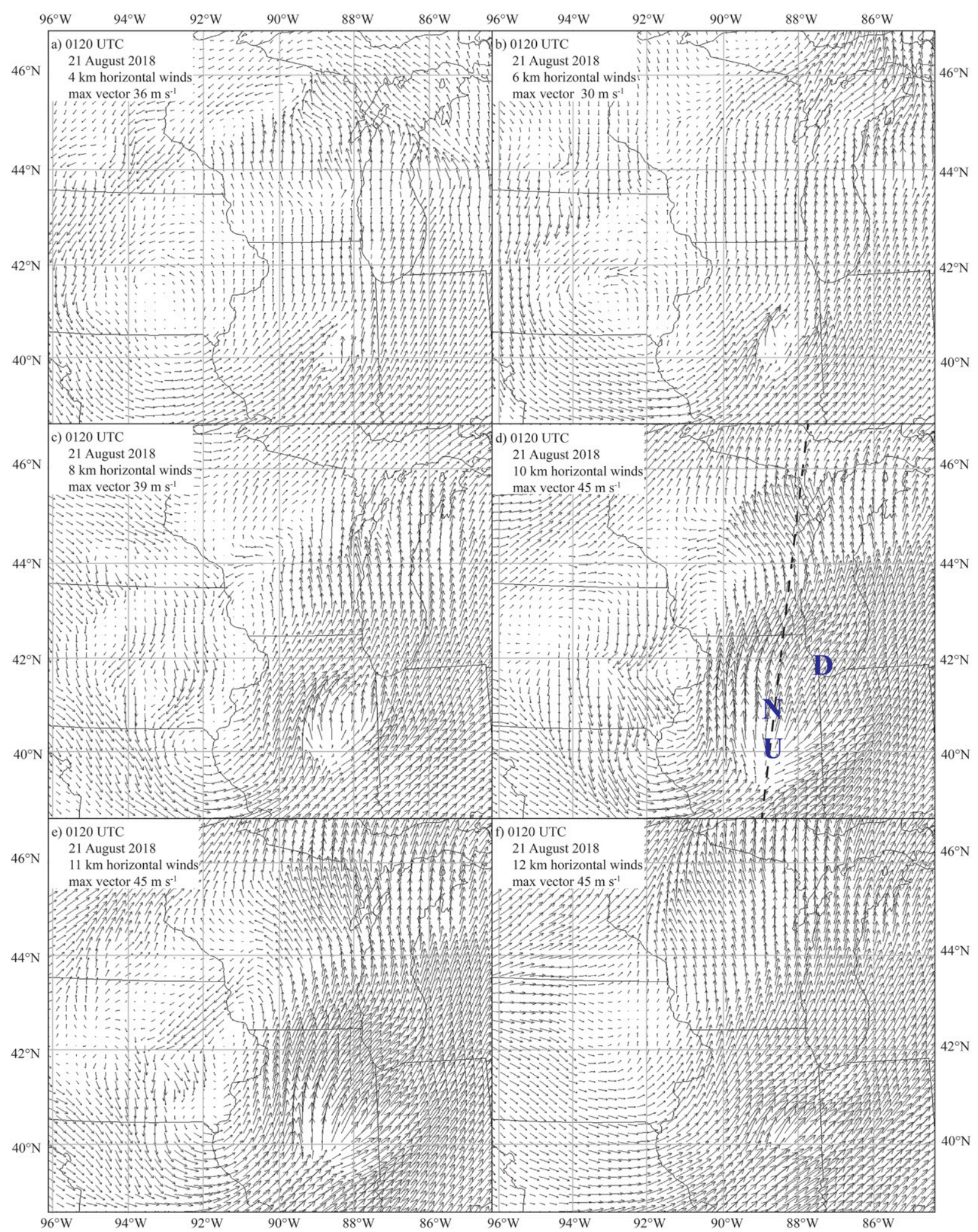

FIG. 8. Horizontal wind vectors in the UWNMS at 0120 UTC 21 Aug 2018 at (a) 4, (b) 6, (c) 8, (d) 10, (e) 11, and (f) 12 km. The maximum vector length is given in each inset. The dashed line in (d) shows the location of the meridional section in Fig. 9. The locations of UWNMS profiles "U," "N," and "D" in Fig. 10 are also shown in (d). 


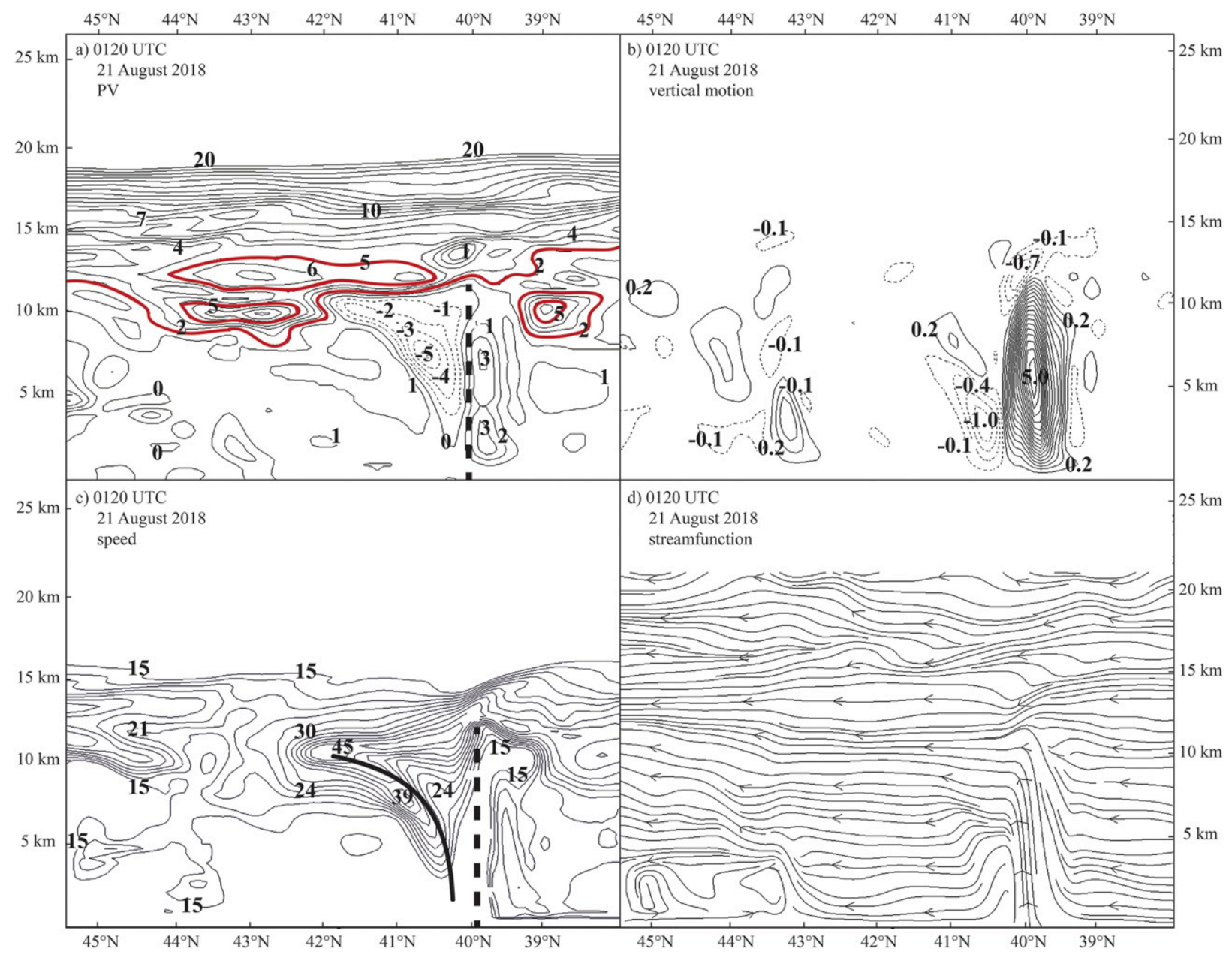

FIG. 9. Meridional section near $88^{\circ} \mathrm{W}$ (location shown in Fig. 8d) at 0120 UTC 21 Aug 2018 of UWNMS (a) PV (interval: 1 PVU), (b) vertical motion (interval: $0.2 \mathrm{~m} \mathrm{~s}^{-1}$ ), (c) wind speed (interval: $5 \mathrm{~m} \mathrm{~s}^{-1}$, starting at $15 \mathrm{~m} \mathrm{~s}^{-1}$ ), and (d) streamfunction in the plane. The axis of maximum vertical velocity in (b) is transcribed onto (a) and (c) as a heavy dashed line. In (a), the 2- and 5-PVU contours are emphasized with thicker contours. The locus of largest values of negative PV within the zero contour in (a) is transcribed onto (c) as a solid curve.

shape or toroid (see Figs. 6 and 9a). This structure at 0300 UTC 21 August is explored in Fig. 11, which shows vertical profiles of PV, meridional wind, and speed, near the end of the most intense precipitation in western Dane County. The profiles were taken in the western part of the PV ring, middle of the negative PV region, and eastern part of the PV ring (locations W, M, and E in Fig. 6d). The positive PV anomaly in the layer 9-12 km maximizes at $\sim 10$ PVU near $10.5 \mathrm{~km}$ in the western part of the ring at location "W" (blue profile in Fig. 11a), while in the eastern part of the ring, the positive PV anomaly maximizes at $\sim 6$ PVU at "E" (Fig. 11c). The negative anomaly in the middle reaches $\sim-2$ PVU near $10.5 \mathrm{~km}$ at "M" (Fig. 11b).

A layer of weaker meridional flow is observed at location "W" (Fig. 6d) in the 9-11-km layer just below the PV maximum (gray profile in Fig. 11a), remnants of the cyclonic, toroidal PV anomaly in the UTLS embedded in a broad poleward surge. In sharp contrast, the poleward flow at " $M$," in the layer of negative PV, exceeds $40 \mathrm{~m} \mathrm{~s}^{-1}$ between 8 and
$12 \mathrm{~km}$ (Fig. 11b). The poleward surge reaches a maximum in the interior of the torus, where the air is inertially unstable.

In Fig. 11c, vertical undulations in horizontal wind are evident throughout the depth of the troposphere and into the UTLS. This is consistent with an increasing emanation of gravity wave activity from the poleward surge and region of inertial instability. The atmosphere tends to restore geostrophic balance and inertial stability by generating gravity waves that radiate away and adjust the overall flow (Rossby 1938; Koch and Dorian 1988).

\section{c. UWNMS trajectories through the positive and negative $P V$ anomalies}

Trajectories in Vis5d were used to track the motion of air through the prominent negative PV anomaly over central IL (X marks in Fig. 7c) and through the positive PV anomaly over northwestern IL (Fig. 7c) at $10 \mathrm{~km}, 0120$ UTC 21 August (Fig. 12). These $\sim 17-\mathrm{h}$ trajectories started at 1220 UTC 20 August and ended at 0540 UTC 21 August 2018. Figure 12b 

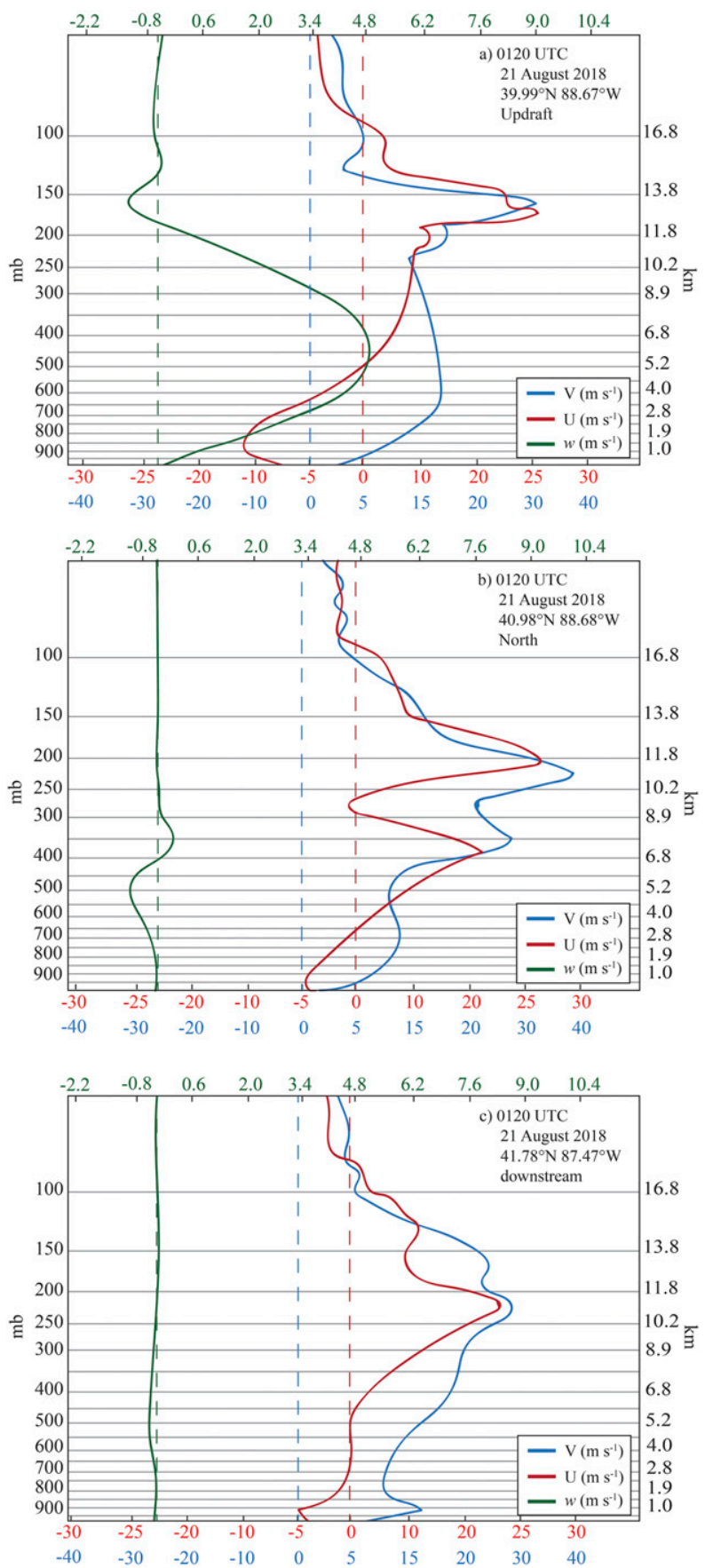

FIG. 10. UWNMS soundings of zonal (red), meridional (blue), and vertical (green) motion $\left(\mathrm{m} \mathrm{s}^{-1}\right)$ at 0120 UTC 21 Aug 2018: (a) in the updraft (location "U" in Fig. 8 d) at $39.99^{\circ} \mathrm{N}, 88.67^{\circ} \mathrm{W}$; (b) north of the updraft (location "N" in Fig. 8d) in the negative PV anomaly at $40.98^{\circ} \mathrm{N}, 88.68^{\circ} \mathrm{W}$; and (c) downstream in the outflow region (location " $\mathrm{D}$ " in Fig. $8 \mathrm{~d}$ ) at $41.78^{\circ} \mathrm{N}, 87.47^{\circ} \mathrm{W}$.

shows an oblique view from above, looking toward the northeast. From this angle, it is evident that the air that creates the negative PV anomaly comes from the boundary layer, rapidly ascends in a convective updraft over IL, and is ejected poleward into juxtaposition with air in the positive PV region. These trajectories show a poleward surge of inertially unstable air toward southeastern WI, which is temporally related to the period of intense rainfall and its cessation.

Figures S4 and S5 show movies, in plan view, of yellow trajectories that intersect the prominent negative PV anomaly over central IL (X marks in Fig. 7c) and green trajectories through the positive PV anomaly over northwestern IL (Fig. 7c) at $10 \mathrm{~km}$, 0120 UTC 21 August, with Fig. S4 showing the positive PV anomalies in yellow, and Fig. S5 showing the negative PV anomalies in green. Note how the trajectories through the negative anomaly ascend through an updraft over central IL and then accelerate poleward. Loop S4 shows the diversion of air with cyclonic PV into southern WI and the subsequent destruction of the PV anomaly. Loop S5 highlights the growth and movement of the -2-PVU isosurface into WI and its connection with air from the upstream boundary layer.

\section{Convective momentum transport and creation of negative PV}

The creation of the deep PV dipole seen in Fig. 9a, and subsequent destruction of the primary PV maximum by injection of inertially unstable air, can be explained in terms of the convective momentum transport hypothesis of Hitchman and Rowe (2019). Figure 13 shows a schematic diagram modified from their Fig. 3a, which is applicable to convection embedded in the poleward upglide sector of midlatitude cyclones. In this case, the ambient flow $v_{a}$ is toward the northeast and increases throughout the depth of the troposphere (Fig. 13a). This northeastward surge is occurring at the synoptic scale, with embedded convective elements. It has been shown that the horizontal speed of the air in the updraft is considerably less than its environment (Fig. 9c). If air at the lifting condensation level (LCL) is transported upward in the updraft, it will have a speed deficit that increases with height, as shown by the horizontal blue arrows in Fig. 13a. At each level, this effectively creates a "jetlet" that opposes the flow. This southwestward-directed, or "negative jetlet," implies a pair of counter-rotating vortices, or vorticity dipole, with an anticyclonic anomaly $\left(\zeta_{3}<0\right)$ to the left, and a cyclonic anomaly $\left(\zeta_{3}>0\right)$ to the right of the ambient flow (Fig. 13b). This result is qualitatively similar to the conclusion by Seman (1994), who carried out idealized nonhydrostatic simulations of MCCs, where convective momentum transport played a key role in fostering the development of combined inertial and convective instability on mesoscale time scales.

The UWNMS calculates the distribution of winds and temperature on altitude surfaces, which can then be used to diagnose the 3D distribution of PV at each time step. The strength of the PV dipole in Fig. 9a increases with altitude until about $7 \mathrm{~km}$, above which an asymmetry in shape develops, due to the poleward tilt of the region of inertially unstable air (Figs. 9a,c). At $6 \mathrm{~km}$, the PV anomalies are $\sim-5$ and +3 PVU. The region of deformation of the northeastward surge by the updraft at $6 \mathrm{~km}$ (Fig. 8b) is flanked by strong zonal gradients of meridional flow to its east and west, especially to the west. Since $(1 / \rho)(\partial \theta / \partial z) \sim 10^{-2} \mathrm{~K} \mathrm{~m}^{2} \mathrm{~kg}^{-1}$ in the midtroposphere, and $1 \mathrm{PVU}=10^{-6} \mathrm{~K} \mathrm{~m}^{2} \mathrm{~kg}^{-1} \mathrm{~s}^{-1}$, one requires relative vorticities 

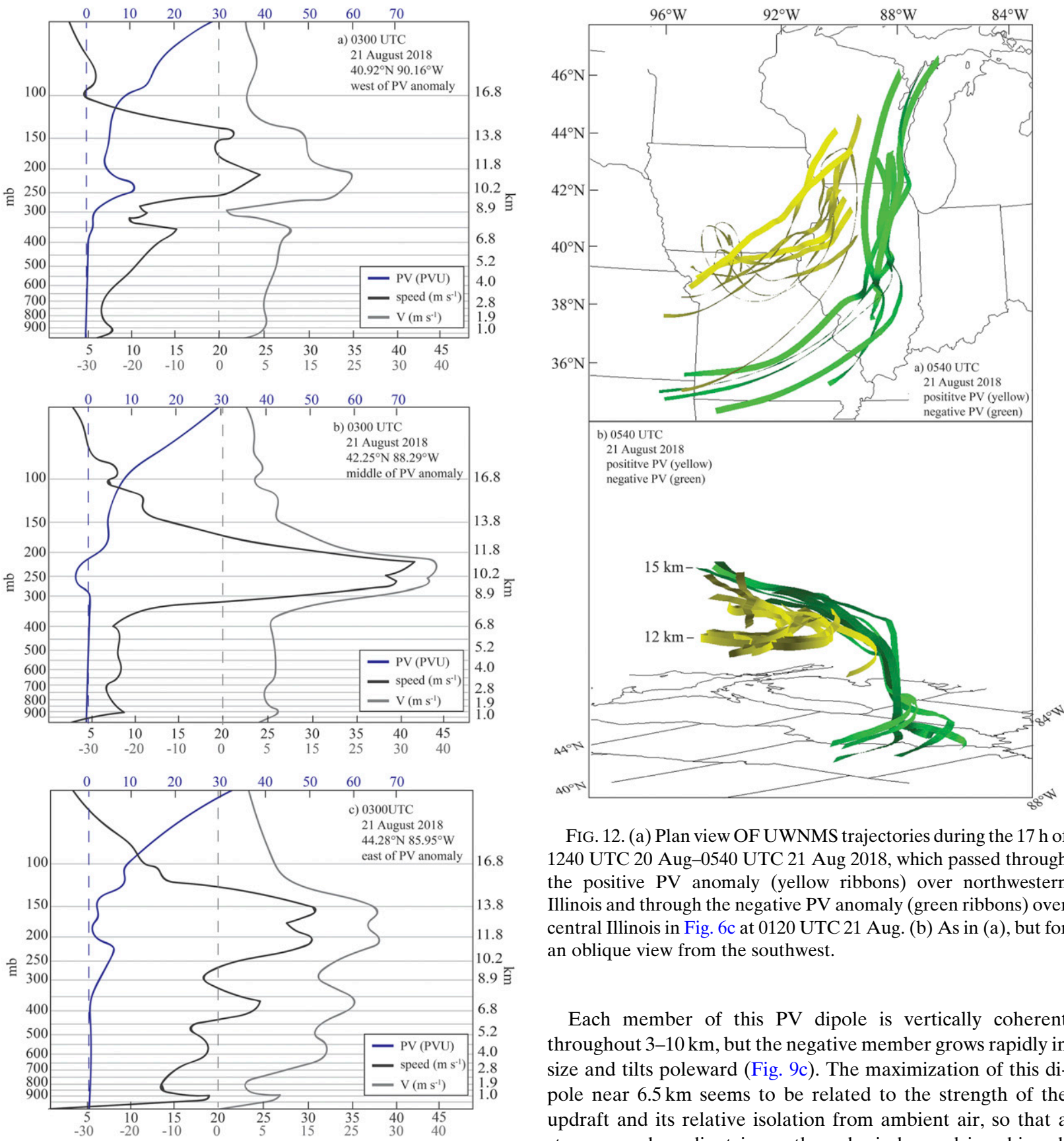

FIG. 12. (a) Plan view OF UWNMS trajectories during the $17 \mathrm{~h}$ of 1240 UTC 20 Aug-0540 UTC 21 Aug 2018, which passed through the positive PV anomaly (yellow ribbons) over northwestern Illinois and through the negative PV anomaly (green ribbons) over central Illinois in Fig. 6c at 0120 UTC 21 Aug. (b) As in (a), but for an oblique view from the southwest.

Each member of this PV dipole is vertically coherent throughout $3-10 \mathrm{~km}$, but the negative member grows rapidly in size and tilts poleward (Fig. 9c). The maximization of this dipole near $6.5 \mathrm{~km}$ seems to be related to the strength of the updraft and its relative isolation from ambient air, so that a strong zonal gradient in northward wind speed is achieved. Hitchman and Rowe (2019) showed that the convective momentum transport viewpoint is intimately related to the vortex tilting mechanism of Davies-Jones (1984, Fig. 7) and Chagnon and Gray (2009, Fig. 9). As the updraft penetrates the synoptic poleward surge, the flow will decelerate due to vertical advection: $\left(v_{a} / \partial t \sim-w \partial v_{a} / \partial z\right.$. Taking the curl of this relation generates a tilting/twisting term: $(\partial / \partial t)\left(\partial v_{a} / \partial x\right) \sim$ $\partial \zeta / \partial t \sim-(\partial w / \partial x)\left(\partial v_{a} / \partial z\right)$. Thus, vertical advection of wind by the updraft corresponds to a tilting term in the vorticity equation. Since ambient shear is toward the northeast, the associated horizontal vorticity is directed toward the north-

west, such that an updraft will tilt horizontal vorticity to point

$10^{-4} \mathrm{~s}^{-1}$, and a $\sim 15 \mathrm{~m} \mathrm{~s}^{-1}$ increase in the northward wind goin eastward $50 \mathrm{~km}$ from the updraft, so that $\zeta_{3} \sim+3 \times 10^{-4} \mathrm{~s}^{-1}$. of order $-5 f$ and $+3 f$, where $f \sim 10^{-4} \mathrm{~s}^{-1}$, to achieve the observed $\mathrm{PV}$ anomalies of -5 and $+3 \mathrm{PVU}$. This is consistent with Fig. 8 b, which shows a $\sim 25 \mathrm{~m} \mathrm{~s}^{-1}$ increase in the northward wind going westward $50 \mathrm{~km}$ from the updraft, so that $\zeta_{3} \sim-5 \times$ 
a)

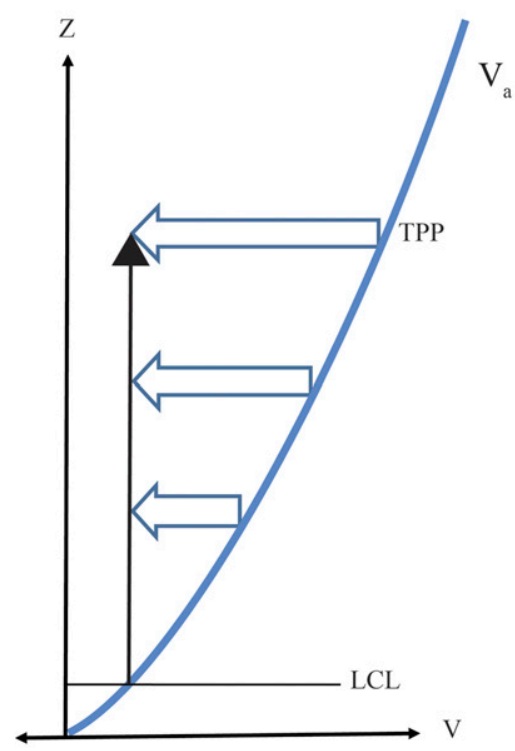

b)

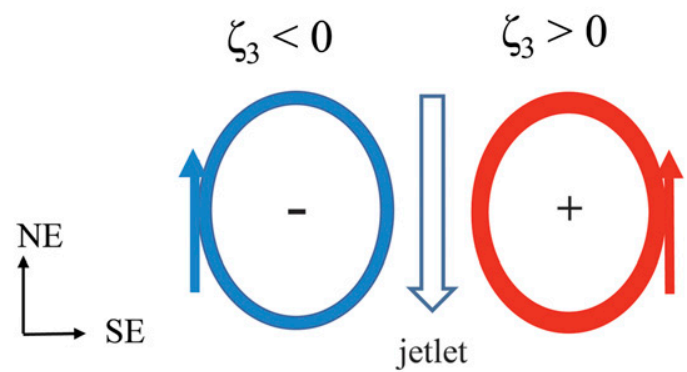

FIG. 13. The vertical momentum transport hypothesis of PV dipole formation applied to the present case of a northeastward surge in a midlatitude cyclone, where speed increases with height to the tropopause (TPP). (a) The horizontal wind speed in the updraft (vertical black arrow) above the lifting condensation level (LCL) is less than the ambient flow $v_{a}$ leading to a "jetlet" at each level, which opposes the ambient flow (blue arrows). (b) The resulting horizontal-plane vorticity dipole will be oriented such that the negative PV anomaly lies to the left of the ambient wind, toward the NW. (Adapted from Fig. 3a of Hitchman and Rowe 2019).

upward to the right of the flow and downward to the left of the flow (cf. Fig. 1 of Hitchman and Rowe 2019). The convective momentum transport hypothesis suggests that injecting slow flow into the upper troposphere creates a speed contrast between the updraft and ambient air, creating a negative PV anomaly to the left of the ambient wind.

As air rises in the updraft, peaking at $\sim 5 \mathrm{~m} \mathrm{~s}^{-1}$, it penetrates ambient shear of $\sim 40 \mathrm{~m} \mathrm{~s}^{-1}$ per $8 \mathrm{~km}$, such that local deceleration in the updraft is of order $\partial v / \partial t \sim-w \partial v / \partial z \sim-1 \mathrm{~m} \mathrm{~s}^{-1} \mathrm{~min}^{-1}$ in the midtroposphere. This is sufficient to account for the observed deficit of speed in the updraft relative to ambient air (cf. Figs. 10a,b). Based on a southwestward acceleration of $\sim 1 \mathrm{~m} \mathrm{~s}^{-1} \mathrm{~min}^{-1}$, a perpendicular spatial scale for the jet of $\sim 50 \mathrm{~km}$, and assuming a midtropospheric static stability factor of $(1 / \rho)(\partial \theta / \partial z) \sim 1 \times 10^{-2} \mathrm{~K} \mathrm{~m}^{2} \mathrm{~kg}^{-1}$, PV anomalies would be expected to increase at a rate of $\sim \pm 0.2 \mathrm{PVU} \mathrm{min} \mathrm{m}^{-1}$, by vertical advection of low-speed air, which would be sufficient to achieve formation of a PV dipole of the observed magnitude in about $20 \mathrm{~min}$.

Further diagnosis of density and pressure anomalies associated with the updraft shows that the density anomaly, $\rho^{\prime}=\rho-\bar{\rho}$, where $\bar{\rho}$ is the domain-averaged density at each level, reaches a maximum negative value near $6.5 \mathrm{~km}$ (not shown), consistent with acceleration up to that altitude, the level of maximum buoyancy due to latent heat release. Near this level, there is a positive pressure perturbation with spatial scale similar to that of the updraft (not shown). Idealized modeling studies of rising thermal bubbles show a positive pressure perturbation at their leading edges (e.g., Fig. 2.7 of Markowski and Richardson 2010). The resulting poleward pressure gradient force is $\sim 30 \mathrm{~m} \mathrm{~s}^{-1} \mathrm{~h}^{-1}$, which is enhanced by about a factor of two relative to surrounding air. This is consistent with the poleward acceleration observed along the flow in the upper troposphere (Figs. 8c,d and 10a,b).

Rappin et al. (2011) and Rowe and Hitchman (2016) argued that a poleward acceleration in an inertially unstable region results from the pressure gradient force exceeding the Coriolis force: $d v / d t=-f u-(1 / \rho)(\partial p / \partial y)>0$ Since inertial instability theory yields the "spring equation" $\ddot{\delta y}=-f(f+\zeta) \delta y$, for meridional displacement $\delta y$, where acceleration can occur in the Northern Hemisphere if $f+\zeta<0$ (inertially unstable). One may estimate the "spring coefficient" $M^{2}=f(f+\zeta) \sim-5 f^{2} \sim-5 \times$ $10^{-8} \mathrm{~s}^{-2}$. Although the time scale associated with $M^{-1}$ is of order 0.5 day, for a meridional displacement of $100 \mathrm{~km}$, meridional accelerations would be $\sim 5 \times 10^{-3}$ or $\sim 20 \mathrm{~m} \mathrm{~s}^{-1} \mathrm{~h}^{-1}$. This is comparable to the observed northward increase in $\mathrm{v}$ along the path of $\sim 40 \mathrm{~m} \mathrm{~s}^{-1}$ in $\sim 400 \mathrm{~km}$ seen in the upper troposphere in Fig. 9c.

The purpose of this study was to try to understand how the stratospheric PV anomaly was destroyed so quickly, and why so much rain fell in southern WI. This led to the realization that there is an interesting role that inertially unstable, poleward flow plays in stalling, and ultimately destroying, the stratospheric PV anomaly. Interpretation and quantification of terms in a PV budget equation are the subject of ongoing consideration in the research community. We have provided an interpretation of its formation in terms of the convective momentum transport hypothesis. In terms of a PV conservation equation [cf. Eq. (4) in Hitchman and Rowe (2019)], it is likely that the "diabatic shear" term is most relevant, since 
the production of the dipole is related to the updraft, which in turn is related to latent heating. However, quantification of PV source terms is outside of the scope of this study, which is to explain the synoptic evolution, rainfall maximum, and destruction of the PV anomaly.

\section{Conclusions}

This study explored the connection between the destruction of a high-PV stratospheric intrusion and an extreme flooding event. The tight roll-up of the UTLS PV anomaly, and its relatively slow motion, led to repeated convective events over southern WI. Its eastward progression was stalled by a poleward surge of inertially unstable air, outflow from deep convection over central IL. More than 11 in. of rain fell over western Dane County, where all of these elements dynamically aligned.

The UTLS PV anomaly initially formed as an instability of a long PV streamer over the west coast of North America, part of a complex chain of Rossby wave breaking events, or PV roll-ups. The PV anomaly of interest acquired a classic "fiddlehead" shape over the upper Midwest as it tracked south of WI. The period of most intense rainfall in Dane County, 1900-2100 CDT, coincided with a northward deformation of the PV anomaly into southern WI by the poleward surge of air over IL. The cessation of rainfall coincided with the arrival of negative PV air and the rapid destruction of the UTLS PV anomaly by admixture of this inertially unstable air.

The UWNMS simulation showed that the lens of high PV in the UTLS was destroyed by convective injection of low-speed air into the UTLS. The contrast between the slow-moving air in the updraft and surrounding air created a pair of counterrotating vortices, or a PV dipole, extending from $\sim 3$ - to $11-\mathrm{km}$ altitude, with the inertially unstable member lying to the northwest. Inertially unstable air in the UTLS then accelerated northward, creating a bow-shaped region of fast, northwardmoving air, which encroached into southern WI. The formation of this PV dipole and its orientation is consistent with the convective momentum transport hypothesis of Hitchman and Rowe (2019). From this point of view, one may consider the low-speed air in the updraft as acting like a backward-stroke by a canoe paddle, creating a pair of vortices by momentum contrast, in this case, extending from the lower troposphere to the UTLS.

Acknowledgments. We would like to acknowledge support from National Science Foundation (NSF) Grants AGS1555851 and 1947658. We thank the National Center for Atmospheric Research (which is funded by NSF) for access to the highresolution ECMWF dataset, and NOAA for providing the NEXRAD, GOES-16, and GFS data. We thank the reviewers for their helpful comments.

\section{REFERENCES}

Advanced Hydrological Prediction Center, 2020: NOAA, accessed 10 October 2018, https://water.weather.gov/precip/.

Ahmadi-Givi, F., C. G. Craig, and R. S. Plant, 2004: The dynamics of a midlatitude cyclone with very strong latent heat release.
Quart. J. Roy. Meteor. Soc., 130, 295-323, https://doi.org/ 10.1256/qj.02.226.

Bithell, M., L. J. Gray, and B. D. Cox, 1999: A three-dimensional view of the evolution of midlatitude stratospheric intrusions. J. Atmos. Sci., 56, 673-688, https://doi.org/10.1175/1520-0469(1999) 056<0673:ATDVOT>2.0.CO;2.

Blanchard, D. O., W. R. Cotton, and J. M. Brown, 1998: Mesoscale circulation growth under conditions of weak inertial instability. Mon. Wea. Rev., 126, 118-140, https://doi.org/10.1175/ 1520-0493(1998)126<0118:MCGUCO>2.0.CO;2.

Bosart, L. F., and F. Sanders, 1981: The Johnstown flood of July 1977: A long lived convective system. J. Atmos. Sci., 38, 1616-1642, https://doi.org/10.1175/1520-0469(1981)038<1616: TJFOJA $>2.0 . C O ; 2$.

Cavallo, S. M., and G. J. Hakim, 2009: Potential vorticity diagnosis of a tropopause polar cyclone. Mon. Wea. Rev., 137, 13581371, https://doi.org/10.1175/2008MWR2670.1.

Chagnon, J. M., and S. L. Gray, 2009: Horizontal potential vorticity dipoles on the convective storm scale. Quart. J. Roy. Meteor. Soc., 135, 1392-1408, https://doi.org/10.1002/qj.468.

Chen, D., and A. Dai, 2019: Precipitation characteristics in the Community Atmosphere Model and their dependence on model physics and resolution. J. Adv. Model. Earth Syst., 11, 2352-2374, https://doi.org/10.1029/2018MS001536.

Craig, G. C., and H. R. Cho, 1992: Cumulus convection and CISK in midlatitudes. Part II: Comma cloud formation in cyclonic shear regions. J. Atmos. Sci., 49, 1318-1333, https://doi.org/ 10.1175/1520-0469(1992)049<1318:CCACIM>2.0.CO;2.

Davies-Jones, R., 1984: Streamwise vorticity: The origin of updraft rotation in supercell storms. J. Atmos. Sci., 41, 2991-3006, https:// doi.org/10.1175/1520-0469(1984)041<2991:SVTOOU>2.0.CO;2.

Davis, C. A., and K. A. Emanuel, 1991: Potential vorticy diagnostics of cyclogenesis. Mon. Wea. Rev., 119, 1929-1953, https://doi.org/ 10.1175/1520-0493(1991)119<1929:PVDOC>2.0.CO;2.

ECMWF, 2016: ECMWF IFS CY41r2 High-Resolution Operational Forecasts. Research Data Archive at the National Center for Atmospheric Research, Computational and Information Systems Laboratory, accessed 15 June 2019, https://doi.org/ 10.5065/D68050ZV

Harnik, N., 2014: Extreme upper level cyclonic vorticity events in relation to the Southern Hemisphere jet stream. Geophys. Res. Lett., 41, 4373-4380, https://doi.org/10.1002/2014GL060009.

Hitchman, M. H., and A. S. Huesmann, 2007: A seasonal climatology of Rossby wave breaking in the 320-2000-K layer. J. Atmos. Sci., 64, 1922-1940, https://doi.org/10.1175/JAS3927.1.

, and S. M. Rowe, 2017: On the similarity of lower stratospheric potential vorticity dipoles above tropical and midlatitude deep convection. J. Atmos. Sci., 74, 2593-2613, https:// doi.org/10.1175/JAS-D-16-0239.1.

, and - 2019: On the structure and formation of UTLS PV dipole/jetlets in tropical cyclones by convective momentum surges. Mon. Wea. Rev., 147, 4107-4125, https://doi.org/10.1175/ MWR-D-18-0232.1.

_- M. L. Buker, and G. J. Tripoli, 1999: Influence of synoptic waves on column ozone during Artic summer 1997. J. Geophys. Res., 104, 26547-26563, https://doi.org/10.1029/ 1999JD900471.

,$--\longrightarrow$, R. B. Pierce, J. A. Al-Saadi, E. V. Browell, and M. A. Avery, 2004: A modeling study of an east Asian convective complex during March 2001. J. Geophys. Res., 109, D15S14, https://doi.org/10.1029/2003JD004312.

Holton, J. R., 2006: An Introduction to Dynamic Meteorology. Academic Press, 535 pp. 
Hoskins, B. J., M. E. McIntyre, and A. W. Robertson, 1985: On the use and significance of isentropic potential vorticity maps. Quart. J. Roy. Meteor. Soc., 111, 877-946, https://doi.org/ 10.1002/qj.49711147002.

Huo, Z., D.-L. Zhang, and J. R. Gyakum, 1999: Interaction of potential vorticity anomalies in extratropical cyclogenesis. Part I: Static piecewise inversion. Mon. Wea. Rev., 127, 2546-2562, https://doi.org/10.1175/1520-0493(1999)127<2546: IOPVAI $>2.0 . \mathrm{CO} ; 2$.

Knox, J. A., 2003: Inertial instability. Encyclopedia of the Atmospheric Sciences, J. Holton, J. Pyle, and J. Curry, Eds., Academic Press, 1004-1013.

—_, and B. D. Hoggatt, 1996: Mesoscale dynamics of midlevel convection in an intense mid-latitude anticyclone. Preprints, Seventh Conf. on Mesoscale Processes, Reading, United Kingdom, Amer. Meteor. Soc., 453-455.

Koch, S. E., and P. B. Dorian, 1988: A mesoscale gravity wave event observed during CCOPE. Part III: Wave environment and probable source mechanisms. Mon. Wea. Rev., 116, 2570-2592, https://doi.org/10.1175/1520-0493(1988)116<2570: AMGWEO > 2.0.CO;2.

Markowski, P., and Y. Richardson, 2010: Mesoscale Meteorology in Midlatitudes. John Wiley and Sons, $407 \mathrm{pp}$.

Martius, O., C. Schwartz, and H. C. Davies, 2007: Breaking waves at the tropopause in the wintertime Northern Hemisphere: Climatological analysis of the orientation and the theoretical LC1/2 classification. J. Atmos. Sci., 64, 2576-2592, https:// doi.org/10.1175/JAS3977.1.

McIntyre, M. E., and T. N. Palmer, 1983: Breaking planetary waves in the stratosphere. Nature, 305, 593-600, https://doi.org/ 10.1038/305593a0.

Nielsen, E. R., and R. S. Schumacher, 2020: Dynamical mechanisms supporting extreme rainfall accumulations in the Houston "Tax Day" 2016 flood. Mon. Wea. Rev., 148, 83-109, https://doi.org/ 10.1175/MWR-D-19-0206.1.

Orellana-Alvear, J., R. Celleri, R. Rollenbeck, and J. Bendix, 2017: Analysis of rain types and their Z-R relationships at different locations in the high Andes of southern Ecuador. J. Appl. Meteor. Climatol., 56, 3065-3080, https://doi.org/ 10.1175/JAMC-D-17-0009.1.

Postel, G. A., and M. H. Hitchman, 1999: A climatology of Rossby wave breaking along the subtropical tropopause. J. Atmos. Sci., 56, 359-373, https://doi.org/10.1175/1520-0469(1999) 056<0359:ACORWB > 2.0.CO;2.

Rappin, E. D., M. C. Morgan, and G. J. Tripoli, 2011: The impact of outflow environment on tropical cyclone intensification and structure. J. Atmos. Sci., 68, 177-194, https://doi.org/10.1175/ 2009JAS2970.1.

Rodrigo, C., S. Kim, and I. H. Jung, 2018: Sensitivity study of WRF numerical modeling for forecasting heavy rainfall in Sri Lanka. Atmosphere, 9, 378, https://doi.org/10.3390/atmos9100378.

Romero, R., G. Sumner, C. Ramis, and A. Genoves, 1999: A classification of the atmospheric circulation patterns producing significant daily rainfall in the Spanish Mediterranean area. Int. J. Climatol., 19, 765-785, https://doi.org/10.1002/(SICI)10970088(19990615)19:7<765::AID-JOC388>3.0.CO;2-T.

Rossby, C.-G., 1938: On the mutual adjustment of pressure and velocity distributions in certain simple current systems. J. Mar. Res., 1, 239-263, https://doi.org/10.1357/ 002224038806440520.

Rowe, S. M., and M. H. Hitchman, 2015: On the role of inertial instability in stratosphere-troposphere exchange in midlatitude cyclones. J. Atmos. Sci., 72, 2131-2151, https://doi.org/ 10.1175/JAS-D-14-0210.1.

—, and — 2016: On the relationship between inertial instability, poleward momentum surges, and jet intensifications near midlatitude cyclones. J. Atmos. Sci., 73, 2299-2315, https://doi.org/10.1175/JAS-D-15-0183.1.

Russell, A., G. Vaughn, and E. G. Norton, 2012: Large-scale potential vorticity anomalies and deep convection. Quart. J. Roy. Meteor. Soc., 138, 1627-1639, https://doi.org/10.1002/qj.1875.

Schultz, D. M., and J. A. Knox, 2007: Banded convection caused by frontogenesis in a conditionally, symmetrically, and inertially unstable environment. Mon. Wea. Rev., 135, 2095-2110, https:// doi.org/10.1175/MWR3400.1.

Schumacher, R. S., and R. H. Johnson, 2009: Quasi-stationary, extreme-rain-producing convective systems associated with midlevel cyclonic circulation. Wea. Forecasting, 24, 555-574, https://doi.org/10.1175/2008WAF2222173.1.

Seman, C., 1994: A numerical study of nonlinear nonhydrostatic conditional symmetric instability in a convectively unstable atmosphere. J. Atmos. Sci., 51, 1352-1371, https://doi.org/10.1175/ 1520-0469(1994)051<1352:ANSONN>2.0.CO;2.

Smith, J. A., A. A. Cox, M. L. Baeck, L. Yang, and P. D. Bates, 2018: Strange floods: The upper tail of flood peaks in the United States. Water Resour. Res., 54, 6510-6542, https://doi.org/ 10.1029/2018WR022539.

Sprenger, M., O. Martius, and J. Arnold, 2013: Cold surge episodes over southern Brazil-A potential vorticity perspective. Int. J. Climatol., 33, 2758-2767, https://doi.org/10.1002/joc.3618.

Stevenson, S. N., and R. S. Schumacher, 2014: A 10-year survey of extreme rainfall events in the central and eastern United States using gridded multisensor precipitation analysis. Mon. Wea. Rev., 142, 3147-3162, https://doi.org/10.1175/MWR-D13-00345.1.

Tripoli, G. J., 1992: A non-hydrostatic mesoscale model designed to simulate scale interaction. Mon. Wea. Rev., 120, 1342-1359, https://doi.org/10.1175/1520-0493(1992)120<1342: ANMMDT $>2.0 . \mathrm{CO} ; 2$.

Whittaker, L. M., and L. H. Horn, 1984: Northern Hemisphere extratropical cyclone activity for four midseason months. Int. J. Climatol., 4, 297-310, https://doi.org/10.1002/joc.3370040307.

Wisconsin Public Radio, 2018: State of emergency declared for Dane County: Officials call for caution after flooding in Dane County. Accessed 11 November 2018, https:// www.wpr.org/state-emergency-declared-dane-county.

Young, C. B., B. R. Nelson, A. A. Bradley, J. A. Smith, C. D. Peters-Lidard, A. Kruger, and M. L. Baeck, 1999: An evaluation of NEXRAD precipitation estimates in complex terrain. J. Geophys. Res., 104, 19691-19703, https://doi.org/10.1029/ 1999JD900123.

Zishka, K. M., and P. J. Smith, 1980: The climatology of cyclones and anticyclones over North America and surrounding ocean environs for January and July 1950-1977. Mon. Wea. Rev., 108, 387-401, https://doi.org/10.1175/15200493(1980)108<0387:TCOCAA > 2.0.CO;2. 